\title{
Energy efficiency in discrete-manufacturing systems: insights, trends, and control strategies
}

\author{
Jenny L. Diaz C.*, Carlos Ocampo-Martinez \\ Automatic Control Department, Universitat Politècnica de Catalunya, Institut de Robòtica i Informàtica Industrial (CSIC-UPC), Llorens i \\ Artigas 4-6, Planta 2, 08028 Barcelona, Spain
}

\begin{abstract}
Since the depletion of fossil energy sources, rising energy prices, and governmental regulation restrictions, the current manufacturing industry is shifting towards more efficient and sustainable systems. This transformation has promoted the identification of energy saving opportunities and the development of new technologies and strategies oriented to improve the energy efficiency of such systems. This paper outlines and discusses most of the research reported during the last decade regarding energy efficiency in manufacturing systems, the current technologies and strategies to improve that efficiency, identifying and remarking those related to the design of management/control strategies. Based on this fact, this paper aims to provide a review of strategies for reducing energy consumption and optimizing the use of resources within a plant into the context of discrete manufacturing. The review performed concerning the current context of manufacturing systems, control systems implemented, and their transformation towards Industry 4.0 might be useful in both the academic and industrial dimension to identify trends and critical points and suggest further research lines.
\end{abstract}

Keywords: Energy efficiency, Energy cost reduction, smart manufacturing systems, energy management, Internet of Things.

\section{Introduction}

The depletion of fossil energy sources, rising energy prices, and governmental regulation restrictions have motivated that many industries around the world have looked at sustainability as a way to reduce their production costs and increase their energy efficiency [1, 2]. These facts arise since industrial sector accounts for more of $30 \%$ of the electrical energy consumption in the world, and the manufacturing industry consumed near to $50 \%$ of that energy, as shown in Figure 1 [3. However, although manufacturing industry is an important share of the worldwide economy, this industry has also significant impacts to environmental dimension due to its high consumption of both renewable and non-renewable materials and production of solid, liquid, and gaseous $\left(\mathrm{CO}_{2}\right.$ emissions) waste streams.

Thus, due to the concern about climate change and the transformation towards sustainable systems, a paradigm shift towards efficient and smart systems has been promoted from the manufacturing industry. Thereby, the energy efficiency issue has gained attention during the last decade, and from this fact, new research trends from different points of view have arisen to try solving this concern. In this sense, different approaches have been addressed, considering from energy sources and their distribution to

\footnotetext{
${ }^{*}$ Corresponding author

Email address: jdiaz@iri.upc.edu (Jenny L. Diaz C.)
}

industries up to the energy use in manufacturing processes carried out by industries. Therefore, some research focuses on finding a more efficient way to supply energy to the industries minimizing the distribution losses and maximizing the power production from renewable energy sources 4, 5, 6. However, the scope of this paper is limited to the energy use in the manufacturing industry and the energy efficiency strategies to reduce energy consumption within a manufacturing plant.

From the manufacturing industry side and sustainability points of view, different proposals have been also addressed. For instance, from the environmental dimension, many of the reported studies focus on developing environmentally friendly technologies by the use of renewable or fewer contaminant materials [7. On the other hand, the economic and technological dimensions have received more attention, mainly due to the profits related to energy cost reductions [8]. In this way, most of the reported improvements in energy efficiency are focused on proposing more efficient designs of the individual components of manufacturing systems, whereas only a few strategies have considered the design of management and control systems of energy consumption for these systems.

The general idea of the strategies currently employed in the manufacturing industry is to reduce the energy consumption of manufacturing systems by optimizing the machining processes, the process planning and scheduling, and avoiding the power peaks during the productive 


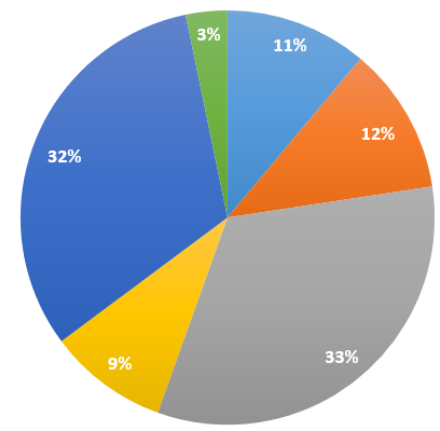

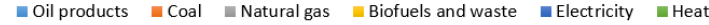

(a) - Industrial sector

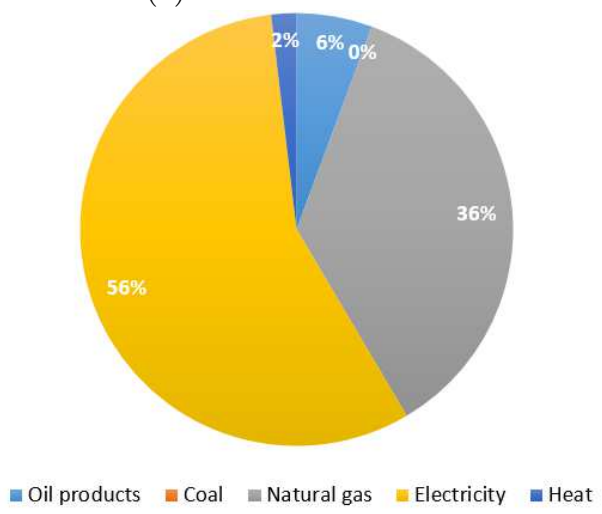

(b) - Machinery industry

Figure 1: Types of energy consumed by (a) industrial sector and (b) machinery industry until 2015 [3].

modes. However, due to the diversity of processes and machinery in a manufacturing industry, many of the proposed strategies are quite restrictive and applicable only to the specific cases in which they were developed. Besides, most of these improvements do not consider the flexibility and smartness requirements of the Industry 4.0 framework [9].

Therefore, to understand the current context of energy efficiency and the future trends and technologies towards the transformation of the manufacturing industry, this paper focuses on exploring current approaches reported in the scientific/industrial literature about these issues and the application of control systems to manufacturing systems during the last decade. Consequently, the general idea of this paper is to serve as a starting point for both manufacturers and academics in further research through identification of the energy saving opportunities and critical points in which control systems can be useful.

In the same direction of this work, other survey papers oriented to the energy efficiency of manufacturing industry have been reported from a seminal work presented by Duflou et al. in 2012 [10. From this work, the study of energy efficiency in manufacturing industry has been divided into levels to ease its comprehension and identification of energy saving opportunities for both the whole plant and its different components. This approach by levels has remained through the works developed during the last decade for studying energy efficiency of manufacturing systems since it allows performing a preliminary decomposition of the large-scale and complex systems in the manufacturing industry. Some of the more recent works reported in 11, 12, 13, 14, 15] present an overview of strategies for energy efficiency and sustainability developed so far for different industrial levels. Similarly, Ingarao [8] focuses on reviewing improvements proposed for manufacturing processes, while Esmaeilian et al. 16] present a review of the new technologies of manufacturing sector focusing on remanufacturing, advanced and additive manufacturing. Nonetheless, none of the proposed works so far looks at the identification of both control techniques and applications of control strategies in the manufacturing industry.

According to proposed objective of identifying the strategies of energy efficiency in discrete manufacturing and recognizing those related to the use of control systems, academic/industrial research published during the last 10 years was searched and deeply analyzed to identify and classify the potential contributions, the type and nature of application, and proposed strategies. Afterward, a qualitative discussion regarding both the reported strategies and the applications of control strategies for improving the energy efficiency of manufacturing systems has been carried out. For this regard, both the focus and the industrial level of application (e.g., machine, line, or plant level) of the studied research were key factors to classify the energy-saving strategies according to specific topics (such as redesign, use of environmentally friendly materials, process optimization, process control, etc.) and, based on this classification, identify the critical points at which control strategies could be useful for the efficient management of energy consumption in manufacturing systems.

Therefore, to provide the suitable overview and discussion of both the proposed strategies and the control techniques conventionally considered to improve the energy efficiency of manufacturing systems, this paper is structured as follows. In Section 2, a brief description of the discrete manufacturing industry considered in this paper and its classification by levels is presented. Next, the identified strategies to improve the energy efficiency of manufacturing systems are presented and discussed in Section 3, while in Section 4 the control techniques applied to these systems are also presented and discussed. Finally, in Section 5, the conclusions regarding the energy saving opportunities and further research are highlighted.

\section{Discrete-manufacturing industry}

According to the literature, different definitions of manufacturing have been proposed. In [17, manufacturing is defined as "a series of interrelated activities and operations involving the design, materials selection, planning, production, quality assurance, management and marketing of the product, and controlling its industrial production". A more straightforward definition of manufacturing 


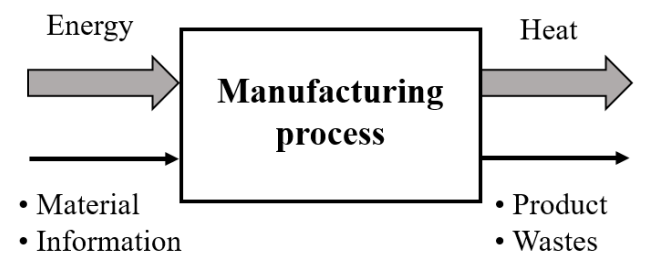

Figure 2: Input/output scheme of a manufacturing process.

is proposed in [16, in which manufacturing refers to the industrial production processes through which the raw materials are transformed into finished products to be sold in the market. In this sense, manufacturing can be considered as a set of processes for transforming resources and energy into industrial products and goods for consumers 18 .

Manufacturing industry can be classified into continuous manufacturing and discrete manufacturing according to the operation modes. In the former, the transformation of raw materials and energy into the desired products implicates changes in both physical and chemical properties of them during the technological processes, which can also constitute diverse operation modes as continuous, quasi-continuous and even batch processes. On the other hand, the discrete manufacturing industry is characterized by single part production, in a discrete-processing mode, and by either physical or mechanical treatments of the raw materials [18. In discrete manufacturing, normally, raw materials are the products of other manufacturing processes, whereas its products are directly used by the final consumers. Some examples of discrete-manufacturing industry are the automotive, aircraft, shipbuilding, and household appliance manufacturing industry.

Manufacturing processes are understood as the technological processes to transform raw materials into products, including their technical and engineering aspects [15, 16]. Thus, manufacturing processes involve a set of technologies and operations used to transform inputs (e.g., energy, material, information) into outputs (products and wastes), which take place in the process units that operate integratively and synergistically to satisfy the final conditions of the desired products. Both inputs and outputs of manufacturing processes can be generalized as shown in Figure 2.

For the case of discrete manufacturing, the most common units used for parts production are the machine tools, and the final conditions of products are mainly referred to physical properties, such as shape, surface, dimensions of the piece, among others. In [10], manufacturing processes are classified into six categories: primary shaping, forming, separating, joining, coating/finishing and those that change the material properties. However, this classification could be limited when new technologies will be considered, and due to this fact, Nassehi et al. [19] proposed a classification based on the type of technology involved, namely, joining, dividing, subtractive, transformative, and additive technologies.

Processes in which two or more workpieces are joint to form fewer workpieces is named as joining technology, while the opposite operation is known as dividing technology, where the resulting workpieces number is higher than the original one. For the case of subtractive technology, the processes are designed to remove material from a workpiece and forming a new part, for instance, by milling and turning [19]. In the transformative technology, a single workpiece is used to produce a new workpiece without changing its mass during the operation, whereas in the additive technology the resulting workpiece has a volume higher than the pre-processed one since new material is either add or deposit for forming the new workpiece.

Additional to manufacturing processes, there exist other technical elements like industrial control systems, industrial robotics systems, assembly systems, material transportation systems, and storage systems, among others, which guarantees the correct operation of a plant [16]. Among these systems, industrial control systems, which refer to all control systems that can be installed in an industrial plant, have been a increasing research topic in order to achieve the objectives of both energy efficiency and production of discrete-manufacturing industry. According to Stouffer et al. 20], control systems encompass several types such as, the Supervisory Control and Data Acquisition (SCADA) systems, Distributed Control Systems (DCS), and the Programmable Logic Controllers (PLC) modules. Indeed, industrial control systems are combinations of control components (e.g., electrical, mechanical, hydraulic, pneumatic) that act together based on set-points, control algorithms, variable and parameter constraints, and process data to achieve a common objective, and which are often found in the critical infrastructures.

In real applications, control systems can be typically configured to operate in open loop, closed loop, or in manual mode and, therefore, they can be automated or include the human intervention into the loop. The openloop and closed-loop control systems can be differentiated based on the output effect over the input. In the closedloop scheme, the output has a direct impact on the input to maintain the set-point or desired objective, while in the open-loop scheme the output is controlled by established settings. On the other hand, in manual mode, the system is entirely controlled by humans 20. For a detailed description regarding different manufacturing systems, the following papers could be considered: 21] about industrial robotics, [16, 22, about assembly systems, [16, 23. about material-handling systems, and 24] for storage systems.

\subsection{Classification by organizational levels}

Due to the large scale and complexity of manufacturing systems, these systems have been studied during last decade by using multi-scale and multi-level research methods [18. Thus, the energy efficiency in manufacturing sys- 
tems has been analyzed according to organizational levels, allowing researchers to analyze manufacturing systems, identify saving opportunities, and propose improvements [25, 26.

Considering the enterprise organization, the disposition and configuration of their devices in the factory, and the relationships between them, different organizational levels for manufacturing systems have been proposed. A first approximation was reported by Herrmann and Thiede [25], in which alternatives for improving the energy efficiency according to three layers, process and machine, the production system, and the technical building services are presented. Afterward, Reich-Weiser et al. 27. propose a decomposition into four levels, covering from the product level up to supply chain of the factory, namely, product, machine/device, facility/line/cell and supply chain level.

Following the idea of analyzing the manufacturing industry by levels, Duflou et al. 10 propose a broader decomposition based on 27] but including all activities of the manufacturing systems. On the other hand, in [15, four levels to study the energy efficiency in manufacturing systems were defined, namely, factory, line, machine and process levels. Unlike the previous classifications, Apostolos et al. 15 separate levels of process and machine, and all improvements directly related to new technologies and parameters of manufacturing process are considering into the process level. Nevertheless, for analyzing the strategies and technologies of energy efficiency of manufacturing systems, only three levels will be considered in this paper. In Table 1, the machine, line/multi-machine, and plant/factory levels are briefly explained.

Based on the previous discussion about technical elements of manufacturing industry, manufacturing processes are related to the machine level, while the multi-step production processes logically organized (sequence or parallel) refer to the line/multi-machine level, namely, manufacturing systems. Then, the association of manufacturing systems with technical equipment and personal corresponds to the higher level of aggregation, the plant/factory level. A representation scheme of the hierarchy of these levels according to the configuration of devices in a automotive part manufacturing plant is presented in Figure 3 . Thus, at the lowest level, manufacturing processes are performed in an arrangement of devices, namely, machine tool, which only does one kind of operation over a piece. Then, more complex structures are found in the process line level, which corresponds to the aggregation of machines, auxiliary devices and buffer devices for producing a piece. At this aggregation level, machines are organized in a logical way according to the required operations to process a piece completely. Since the machines in a process line can have different operating cycles, buffers are required in order to maximize the production and avoid the simultaneous input of two or more pieces to one machine. At both machine and line levels, auxiliary devices to guarantee the correct operation of machines and the suitable supply of resources to machines are required. Besides, when in addi- tion to these devices, all the TBS and technical personnel are considered, the higher level of aggregation (plant level) is achieved. Into the plant level, all devices involved in both value and non-value task in a factory are considered. Thus, according to Figure 3 it is possible to observe that the dynamics and interactions between the elements of a level can directly affect the components of higher levels and therefore their energy consumption. From this fact, a detailed knowledge of each level, its elements, and its interactions will be necessary for establishing a real context from which the improvements in energy efficiency can be developed.

\subsubsection{Machine level}

Machine level is focus on the machine tools, which are defined as complex systems composed of different components such as cooling units, pumps, spindles, drives, and peripheral devices (e.g., control units) that contribute to the total electrical power of the machine [29. On the other hand, Zein [17] refers to a machine tool as a set of integrating parts and moving components enabling the entire system to perform a complex function, such as the geometric forming, shaping or joining of workpieces by using the appropriate tools and technologies. This latter definition regards the machine tool as a type of the metalworking machinery, which have drive systems different to human effort and work for a fixed period (cycle).

The components of the machine tool can be divided into the primary-function and peripheral devices. The former are the elements directly involved into shaping or joining of workpieces while the peripheral devices guarantee the operating conditions needed for performing the primary function. Usually, the main components operate in a fixed sequence for producing a piece and, based on this, the time of cycle of the machine is defined. On the other hand, the peripheral elements could or could not work during a typical cycle of main elements, i.e., some of the peripheral devices can activate at each two or more cycles of normal operation. Indeed, switching on or off the peripheral components is a critical factor to reduce the energy consumption of machine tools.

According to $\mathrm{Hu}$ et al. 30, the activities with highest energy demand in a machine tool are the spindle rotation and the servo-driven axis motion, which are directly involved into processing of a workpiece (cutting, milling, turning, etc.). In Figure 4 the energy consumption of a machine tool is decomposed in low, medium, and high consumers according to 31, 32. Based on main consumers in a machine tool and its periodic behavior, different operating modes can be distinguished during an operation cycle of a machine. These modes refer to the different processing stages (and of energy consumption) of a machine to completely process a piece. Therefore, the energy consumption profile of a machine is determined by the process and individual machine features.

In 29, 33, the operating modes of a machine tool are classified as the modes on, standby, process and off, while 
Table 1: Decomposition levels considered for the manufacturing industry. Based on 10].

\begin{tabular}{ll}
\hline Level & Description \\
\hline \hline Machine & Individual device or machine tool in the manufacturing system in \\
& which processes take place. Includes support equipment. \\
Line/multi- & $\begin{array}{l}\text { Logical organization of machines or devices that are acting either } \\
\text { machine }\end{array}$ \\
$\begin{array}{l}\text { in series or parallel to execute a specific activity. Includes support } \\
\text { equipment for the collection of devices as chip conveyors. }\end{array}$ \\
$\begin{array}{l}\text { Distinct physical entity housing multiple devices, which may or } \\
\text { may not be logically organized into lines, cells, etc. Includes sup- } \\
\text { port equipment required at the facility. }\end{array}$ \\
\hline
\end{tabular}
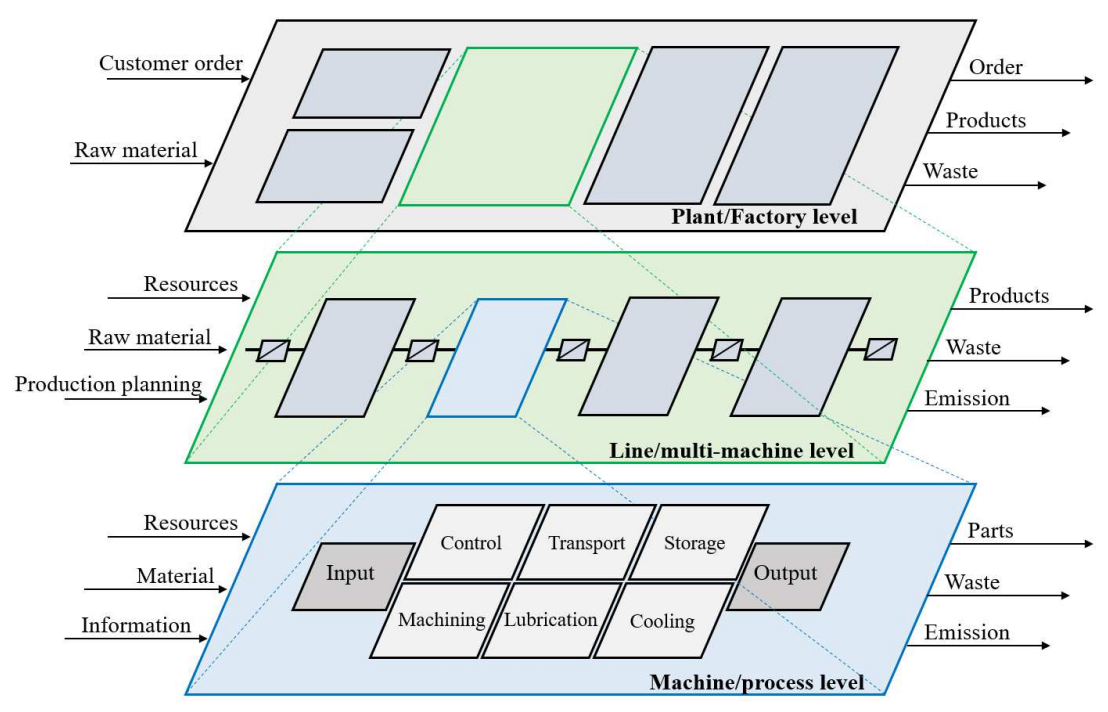

Figure 3: Classification by levels of manufacturing industry. Based on 28.

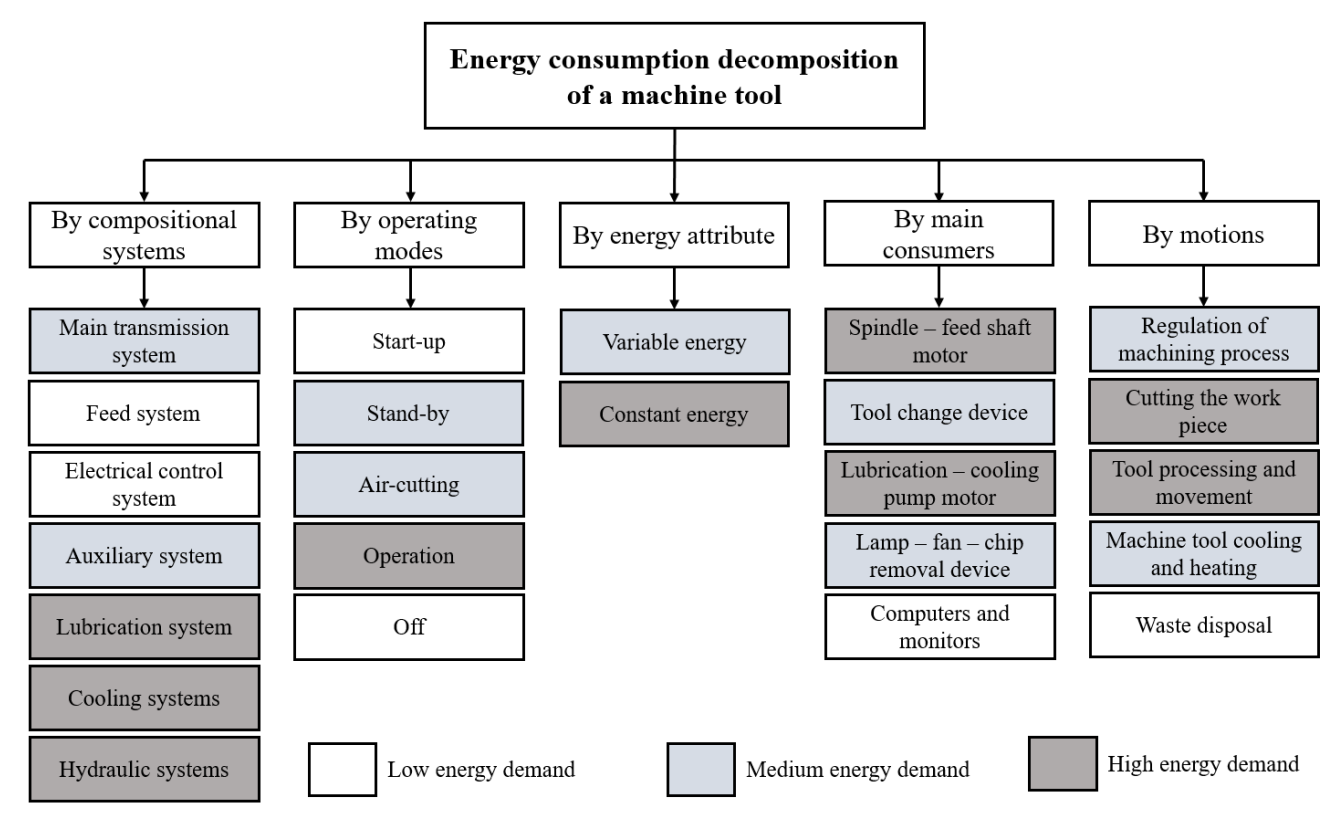

Figure 4: Energy consumption decomposition of a machine tool [31, 32]. 
Zhou et al. 31. propose a detailed classification of operating stages for a milling process. In this latter, the start-up, standby, air-cutting, operation, and off status are identified from an energy consumption profile of a machine tool. These modes indicate the different power levels and activation times related to the operating machine states, in which the start-up corresponds to the turning on of the machine, while the standby mode regards the electrical energy used to activate the machine components and to ensure the operational readiness of the machine. Air-cutting mode can occur several times during the machine operation, e.g., after the machine is started and before cutting, and between different cutting stages. Thus, more energy is required for the drives and spindle, e.g., to move, to change the tool, to clam the piece, to bring the tool, among others. Then, during the operation stage, the energy is consumed at the tool tip to remove piece material, i.e., during the machining process. Finally, the off mode corresponds to switching off the machine, in which the power demand is null. Thus, according to technology employed and the operations performed, the operating modes of any devices could be determined from the energy consumption profile and through the information coming from CNC. For instances, the operating modes of a machine tool can be identified based on the activation of its components for preparing the material removal, the waiting time of elements during changes of tools or pieces, as well as the spindle activation for removing the material. A typical energy consumption profile of the milling process with its operating modes is presented in Figure 5.

Taking into account the operating modes of a machine tool, its energy consumption is divided into the constant and variable energies. The former category is related to the energy consumption of both start-up and standby modes, such as activation of peripheral devices, unloaded motors, conveyors, control units, tool change, among others, while the variable energy refers to the power consumption during the machining process. Hu et al. [30] define the variable energy as the energy used to cut materials, i.e., it depends on the machining process performed, whereas the constant energy is independent on machining and refers to the power consumed by the machine in a ready-for-operating mode. Indeed, depending on the type of machine tool, different energy consumption profiles, operating modes, and portions of constant and variable energy can be distinguished [10, 17, 28, 34. Therefore, due to the different production processes performed in a machine and their associated operating modes, it is necessary to understand and analyze the energy consumption behavior of such machine to propose improvements that allow reducing the energy consumption.

\subsubsection{Line level}

A process line refers to a collection of machines organized in a proper configuration for producing a finished piece. Among the machines that form a process line, it could exist other peripheral devices in addition to those that guarantee the operation of a machine tool. Duflou et al. 10 define a process line as a multi-machine ecosystem that describes a network of machines within a factory. According to the processes performed on each machine and its connections, process lines present different configurations such as serial and parallel structures as shown in Figure 6. Thus, based on the configuration of machines in a process line, the operation of one machine could depend on the correct operation of previous machines, as in serial configuration, while in a parallel configuration the operations of machines could be independent on other ones in the line.

Thereby, according to configurations in a process line different energy and material flows, which represent either the interactions or relations between the machines in a line, could be existed. These relations add complexity to understand and model the energy consumption at this level. Therefore, factors as the diversity of components in a process line, their energy consumption behavior, their interactions, and the intrinsic characteristics of each component should be considered to analyze and propose energy efficiency improvements at process line level 35.

\subsubsection{Plant level}

In the same way as the process line, the plant level consists of arrangements of process lines and auxiliary devices that guarantee the operating conditions of both each process line and its working environment. Wahren et al. [36] consider that most of the energy in a factory would be used for peripheral applications and processes in nonvalue added sectors. Therefore, regarding energy flows at this level, the existing relations among machines and the working environment should be analyzed. Herrmann and Thiede 25] defined a production plant as an integrated system that comprises three partial systems: the production system itself, the Technical Building Services (TBS) and the building. The former refers to the interlinked machines and the personnel controlled through production management. On the other hand, TBS ensure the required production conditions of temperature, moisture, and purity through cooling/heating and conditioning of the air, besides of supplying energy, compressed air, steam or cooling water required for machines [37, 38, 39].

Taking into account that in a manufacturing plant the energy costs are not only determined by its consumption but also by surcharges due to peak loads, the energy consumption profile of both the productive and nonproductive systems in a manufacturing plant should be analyzed. This latter fact is given by the simultaneous activation of different production processes, machines, and auxiliary devices, which results in a cumulative load that could increase the energy costs. Thus, in order to identify the critical components and propose measures for improving energy efficiency in a manufacturing plant, it is necessary to analyze the energy profile of all machines and the TBS to avoid both increases of the energy consumption and surpasses the contracted load. 


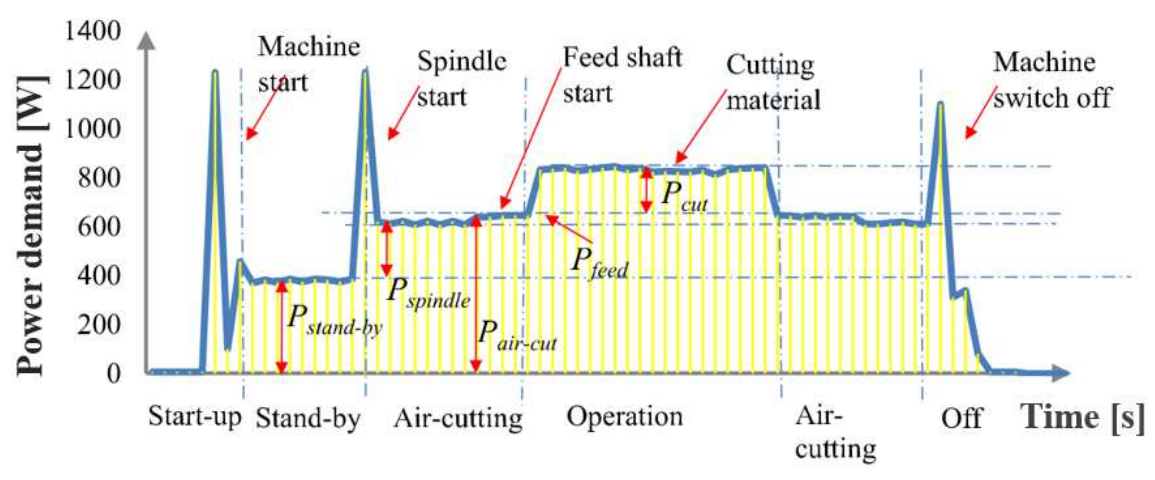

Figure 5: Energy consumption profile of a milling process with $P_{i}$ the required power in each operating mode. Taken from Zhou et al. 31].

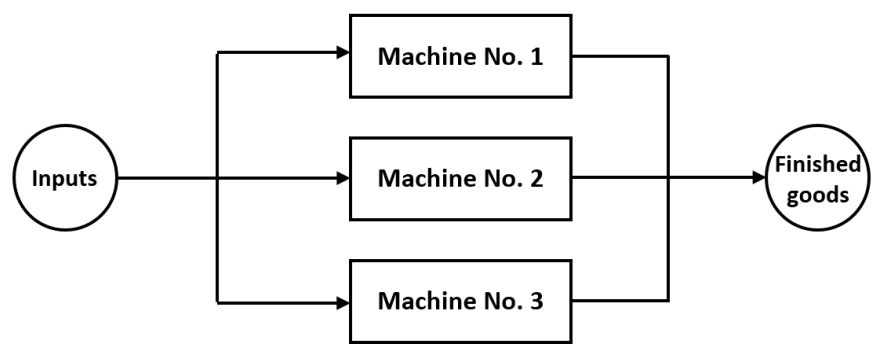

(a) - Parallel configuration

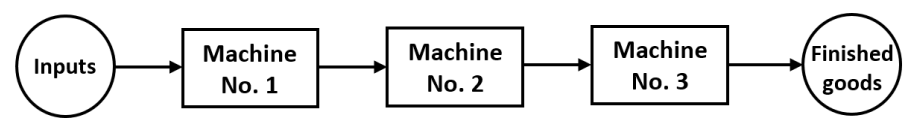

(b) - Serial configuration

Figure 6: Configuration in parallel (a) and serial (b) of machines in a process line.

\section{Energy efficiency of manufacturing systems}

Due to the nature of manufacturing processes, manufacturing industry consumes both renewable and nonrenewable resources, such as energy, water, metals, among others, producing a significant impact on the environment. As a consequence, solid, liquid, and gaseous waste are generated during the manufacturing processes. Based on this fact, nowadays, there exist an increasing interest of manufacturing enterprises to look for new technologies and strategies that allow reducing both the energy and production costs and making an efficient use of resources. Thus, taking into account the manufacturing sector accounts for one-third of global primary energy consumption, with more than $38 \%$ of direct and indirect $\mathrm{CO}_{2}$ emissions [12], the energy consumption is a crucial factor due to its implications at ecological and economical levels [25].

Traditionally, the performance of manufacturing systems has been addressed considering factors such as time, cost, quality, and flexibility, but in the new era of sustainable manufacturing, the resources and energy use should be considered into the efficiency analysis of manufacturing systems 26, 40. Although the need of improving the energy efficiency of manufacturing systems is clear, there exist barriers and encouraging elements that limit and promote energy efficiency improvements, respectively. May et al. 12] define the barriers as the main inhibitors for a company on the way to implement environmentally and economically efficient measures while the encouraging elements are considered as the stimuli that motivate companies to achieve improvements in energy efficiency. Different studies have focused on the identification of barriers and promoters for the implementation of energy reduction strategies in a factory [11, 12, 26].

In general terms, the energy efficiency of manufacturing systems can be defined as the relationship between the productive output of production systems and the total energy supplied to them (e.g., oil, gas, electricity, heat) [26. 41]. Nevertheless, depending on the established levels, the systems, outputs, and inputs can be differently understood, and the energy efficiency definition will be different for each level.

\subsection{Energy efficiency by levels}

Since the concept of energy efficiency could be understood and defined in different ways according to level addressed, a brief definition of energy efficiency for each man- 
ufacturing level is introduced in this section. Afterwards, strategies and techniques proposed in literature for improving this feature are presented and discussed.

\subsubsection{Machine level}

Although many energy efficiency definitions have been proposed in literature [15, 17, 26, 28, they are not clear enough due to the diversity and complexity of the machines. Apostolos et al. [15] define the energy efficiency at machine level as the relation between the energy provided to the process and that consumed by the machine. On the other hand, in 28] an energy efficiency definition based on the power demand was proposed and expressed as follows:

$$
\eta_{E}=\frac{N_{w p}}{E_{d} t}
$$

being $N_{w p}, E_{d}, t$, the number of produced pieces, the electrical power demand, and time, respectively.

Then, Zhou et al. 31] introduce a detailed definition of energy efficiency in which it is divided into two types. First, the process energy efficiency refers to the relation between the effective energy and the energy consumed by the device in a finite time. Second, the instantaneous energy efficiency expresses the ratio of material removal cutting power and the machine input power. Indeed, and according to Zein [17, energy efficiency at machine level concerns to the improvement of the input-output relations of existing transformation processes towards either minimum input or maximum output levels. In addition, the use of evaluation indicators of energy efficiency of machines has been introduced for quantifying and tracking the machine efficiency.

Schudeleit et al. 29] have summarized and classified the energy efficiency indicators at machine level based on three strategies to foster environmental improvements in the context of sustainability. Among these indicators, it can be highlighted the Energy intensity (EI), the Specific Energy Consumption (SEC), the Energy Efficiency Ratio (EER), the Energy Conversion Efficiency (ECE), and the Energy Efficiency Index (EEI). Then, a new metric for quantifying the machine tool energy efficiency based on the energy efficiency of machine components is proposed. Among them, the SEC index has had a great application for determining the machine energy efficiency (or machining process efficiency) [10, 31, 42, 43. Zhou et al. 31. define SEC as the energy required to remove material per unit volume or mass, i.e., it expresses the relationship between energy consumption and process variables as follows:

$$
S E C=\frac{E}{V_{m}},
$$

with $E$ and $V_{m}$ expressing the energy required by the machine in $[\mathrm{J}]$ and the total volume of removed material $\left[\mathrm{m}^{3}\right]$, respectively. Equation (2) is related to the energy efficiency of the entire machine since it considers both operational and non-operational modes. Also, $V_{m}$ is directly related to the Material Removal Rate (MRR), which refers to the volume or quantity of removed material per unit of time. Besides, SEC is also used as a model of energy consumption since it expresses the energy efficiency level from the perspective of the machine effective input and output. For instance, in [44, 45, 46] the concept of SEC is used to determine the relations between process variables and energy consumption in machine tools.

\subsubsection{Process line and plant level}

Although at both the line and plant levels it is more difficult to define the energy efficiency than at the machine level due to the existence of complex relations among machines and their different configurations, peripheral devices and the working environment, Thiede 28] proposes a simplified expression of the energy efficiency for both a process line and plant level as follows:

$$
\eta_{E}=\frac{P_{\text {out }}}{E_{\text {in }}},
$$

being $P_{\text {out }}$ and $E_{\text {in }}$ the produced output as the number of pieces and the total energy input to the system in $[\mathrm{J}]$, respectively. Even though (3) is quite general, the energy efficiency evaluation can be improved if the system boundaries (e.g., according to manufacturing level) and both the input and output variables are correctly defined. Thus, based on (3), it is possible to observe that strategies that allow minimizing the total energy input while keeping the production output or maximizing the production output without increasing the energy consumed can contribute to improve the energy efficiency of manufacturing systems.

Thus, regarding machine level, (1) can be more suitable to compare the mass production and the energy consumed by all elements of the machine, while (2) is more related to the efficiency of the manufacturing process performed in the machine. On the other hand, with respect to both the process line and plant levels, the energy-efficiency indicators have been proposed in a similar way to (3). Indeed, due to the diversity of processes performed at these levels, it is more convenient to evaluate in a general way the consumed energy according to the number of produced pieces.

Finally, the use of key performance indicators depends on the level and application for which they will be analyzed since most of them are designed to express a relationship between one specific production activity and the energy consumed to achieve it. Therefore, according to the application and the industrial level considered, some energy efficiency indicators could be or could not be compared. Bunse et al. 47. presents a classification to analyze the different energy efficiency indicators, their formulas, and their application cases. According to this work, there exist different energy efficiency indicators because of the great variety of industries and manufacturing process, and therefore, some indicators could be more suitable than others at each level. For instance, at plant level, the Energy Performance Index (EPI) is an indicator used for benchmarking energy usage per unit area, from which the energy consumption of TBS can be properly considered. Thus, due 
to the complexity of the industrial processes and different applications of energy efficiency indicators, Schmidt et al. 48. propose a classification and a generalized calculation methodology by using templates for measuring the energy efficiency of manufacturing activities, and considering from factory level to process and product levels.

\subsection{Strategies and technologies of energy efficiency}

For producing a behavioral shift towards efficient and sustainable manufacturing industry, the relations between the companies and governmental institutions, as well as the technological developments must be considered. From this fact, different studies have focused on the identification and categorization of barriers and the encouraging elements of energy efficiency in manufacturing systems [49, 50]. Moreover, several studies have been developed throughout the last decade to provide a general context about the techniques and strategies implemented for improving the energy efficiency of manufacturing systems.

Yoon et al. 44 perform a review mainly focused on machine tools in manufacturing industries, in which different techniques for assessing and modeling the fixed and variable energy consumption of these machines are presented. Besides, optimization techniques for process planning, tool path generation, and scheduling of single devices are broadly reviewed, while analyzing the impacts on the energy efficiency of MRR and of assisted machining systems (e.g., Laser-Assisted Machining (LAM)). Esmaeilian et al. [16] have studied the evolution of research in manufacturing systems from past and current trends to future developments. This latter work mainly aims to review the current trends in manufacturing systems such as advanced, smart, cloud, and sustainable manufacturing, Cyber-Physical Systems (CPS), and remanufacturing.

On the other hand, Zhou et al. 31 focus on the identification of main energy consumers in a machine tool and, based on this, different energy consumption models that take into account the process, machine tool, and tool features are presented. Other alternatives oriented to reduce the processing time by either increasing the process rate, optimizing the machine tools architecture, and using control systems for the selective activation of machine tool components are presented in [8, 13]. Additional to these works, several works have been developed with the same aim of collecting the strategies implemented by manufacturing industry to satisfy its requirements of energy and resource savings. Thus, in Table 2 the identified categories for improving energy efficiency are summarized based on the reviewed workers/papers and, according to the classification by levels previously presented in Section 2.1. From Table 2 , it is possible to observe that most of the proposed approaches have been focused on the machine level, following the idea that an improvement in a lower level would be reflected in higher levels and, therefore, contribute to improving the energy efficiency of the entire system.

Park et al. 38, study the energy policies, the energysaving methods, and the energy consumption reduction strategies currently implemented in countries of the European Union (EU), Japan, and North America. Besides, the authors present the trends in research directions and identify the energy saving opportunities for the manufacturing systems. Thus, according to last work, energy efficiency in manufacturing systems has been recognized as the most critical research issue in the near future by the EU. Therefore, research topics such as energy-aware manufacturing processes (measurement and control), energy efficient production management systems, advanced automation for demanding process conditions, maintenance concept for energy efficiency, electrical energy operations in off-peak hours, among others related to the emission reduction technologies (e.g., eco-design and environmental assessment) have gained attention into the industry.

Most of these works attempt to introduce a state-of-theart regarding the strategies, methodologies, and technologies considered by levels, with the aim of getting significant energy and resource reductions in the domain of discrete manufacturing. However, a significant part of strategies studied are focus on machine level, in which three main research topics can be defined for classifying the reported research: optimization of machine design, optimized process control, and process/machine selection. The improvements collected in these categories address topics related to the use of more efficient components for the machine tools, improvements of current technologies, the recovery of waste streams and heat losses within a machine tool, and searching an optimal energy and resources use that allow reducing energy waste.

On the other hand, alternatives to manage the devices in a machine tool without modify the design of either machine or peripheral devices have been developed focus on integration or centralization of peripheral devices, selective shutting off of devices, reduction of the idle time, optimization of process parameters, and processes modeling, planning, and scheduling. These latter strategies change the way as devices are managed without affecting the main operation of the machine, and unlike of re-design strategies they reuse the available technologies and machinery avoiding significantly increasing costs.

Since the diversity of machines and the machining processes, their complexity and their different components (primary-function and peripheral devices), strategies for optimizing the machine configuration and components design, as well as optimization of process parameters have been broadly studied during the last decade. However, taking into account the environmental impact and the search towards sustainability of manufacturing systems, other alternatives such as the implementation of recovery systems within machines, the use of alternative fluids for lubrication and coolant systems, the selection of more sustainable machining processes, and the optimal resources selection have been of great interest for the manufacturing industry. In addition, many studies related to the implementation of control systems for monitoring the energy efficiency and the switching on/off of machine compo- 
Table 2: Classification of relevant reported research about the current context of energy efficiency improvements in manufacturing industry regarding both the approaches addressed and the focusing level.

\begin{tabular}{|c|c|c|c|c|c|}
\hline \multirow[b]{2}{*}{ Reference } & \multicolumn{2}{|c|}{ Key approaches } & \multicolumn{3}{|c|}{ Focus level } \\
\hline & 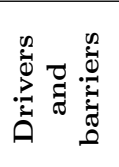 & 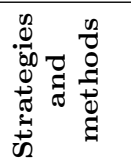 & 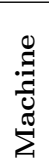 & 胥 & 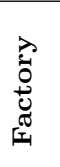 \\
\hline May et al. [12] & $\mathrm{x}$ & $\mathrm{x}$ & $\mathrm{x}$ & & \\
\hline Trianni et al. [1] & $\mathbf{x}$ & & & & $\mathbf{x}$ \\
\hline Esmaeilian et al. [16] & & $\mathbf{x}$ & $\mathbf{x}$ & $\mathbf{x}$ & \\
\hline Yoon et al. 44 & & $\mathbf{x}$ & $\mathbf{x}$ & & \\
\hline Cagno and Trianni 51 & $\mathbf{x}$ & & & & $\mathbf{x}$ \\
\hline Brunke et al. 49 & $\mathbf{x}$ & & & & $\mathbf{x}$ \\
\hline Cagno and Trianni 50 & $\mathbf{x}$ & & & & $\mathbf{x}$ \\
\hline Ingarao 8 & & $\mathbf{x}$ & $\mathbf{x}$ & & \\
\hline Park et al. 38 & & $\mathbf{x}$ & $\mathbf{x}$ & $\mathbf{x}$ & $\mathbf{x}$ \\
\hline Herrmann and Thiede 25 & & $\mathbf{x}$ & & & $\mathbf{x}$ \\
\hline Duflou et al. 10 & & $\mathbf{x}$ & $\mathbf{x}$ & $\mathbf{x}$ & $\mathbf{x}$ \\
\hline Apostolos et al. 15 & & $\mathbf{x}$ & $\mathbf{x}$ & & \\
\hline Yingjie 14 & & $\mathbf{x}$ & $\mathbf{x}$ & & \\
\hline Salonitis and Ball [26] & & $\mathbf{x}$ & $\mathbf{x}$ & & \\
\hline
\end{tabular}

nents to reduce the idle time, even for the activation of either centralized or non-centralized peripheral devices, have been developed. However, this latter approach has promoted research about more precise modeling techniques, simulation tools, and robust control systems to obtain better energy consumption models, and even to add predictive behaviors to the control systems design. In Table 3, a classification of the technologies applied at machine/process level during the last decade is presented.

Continuing with the second level, due to the diversity of machines in a process line, besides of material removal, different operations such as heat treatments, transportation and material handling, fluids transport, among others, can take place in the process-line machines. Nonetheless, to obtain energy-efficient systems at line level, the improvements for each machine or individual device in the process line are not enough, and instead of this, the whole process line should be optimized to reduce its total energy consumption [21]. According to this, at line or multi-machine level, some of strategies and technologies identified from literature are focused on capture and track energy and material flows in a multi-machine ecosystem, the processes planning and scheduling of machines and their integration.

Process planning and scheduling are essential and complementary factors regarding energy consumption and flexibility of manufacturing systems. Conventionally, the scheduling is made after the processes planning stage, and in most of the cases, only a process planning is considered for the manufacturing of a piece. Regarding this issue, the currently implemented strategies in manufacturing systems have focused on the development of adaptable and sustainable processes plans, which can be flexible regarding the energy and market requirements. In the work of Bruzzone et al. 88, an approach of integration between the Energy-Aware Scheduling (EAS) methodology and a reference schedule generated by an Advanced Planning and Scheduling (APS) system that does not consider energy saving is proposed. This approach is employed together with a process model to control the power peaks in the shop floor for a given detailed schedule. Thus, the proposed method, which is based on a Mixed Integer Programming (MIP), modifies an original timetable of APS to reduce the power peaks in a process line.

Similarly, Lu et al. 89] study the energy-efficient Permutation Flow-shop Scheduling Problem with Controllable Time (PFSPCT) with the aim to analyze the scheduling problem but including both transportation and processing times. Thus, in order to formulate the problem scheduling, a multi-objective optimization problem that considers both the make span and the energy consumption of a machine cycle is introduced, while a Hybrid Multi-Objective Backtracking Search Algorithm (HMOBSA) is proposed to solve such an optimization problem. A different approach that incorporates power models for a single machine and cutting parameters optimization into the scheduling problems is developed by Yan et al. 72. In this work, the scheduling problem is solved by using a multi-level optimization approach considering both the machine and line levels. At machine level, the cutting parameters of each machine are optimized using grey relational analysis for determining the weight coefficient of the two objectives to be minimized: the cutting energy and cutting time. Then, based on an energy consumption model for a flexible flow-shop, a genetic algorithm is used to optimize both the make span and the total energy consumption simultaneously. In another way, the issue of integration of pro- 
Table 3: Research topics for improving the energy efficiency at machine level.

\begin{tabular}{|c|c|c|}
\hline Category & Approach & Reference \\
\hline \multirow{4}{*}{$\begin{array}{l}\text { Optimization } \\
\text { of the machine } \\
\text { design }\end{array}$} & More efficient components & {$[39,52$} \\
\hline & Technological changes & $39,53,54,55,56$ \\
\hline & Recovery systems for machines & 57,58 \\
\hline & Integrated or central peripheral devices & 32,52 \\
\hline \multirow{4}{*}{$\begin{array}{l}\text { Optimized } \\
\text { control }\end{array}$} & $\begin{array}{l}\text { Selective actuation of } \\
\text { continuously-required devices }\end{array}$ & 63, 59, $60,61,62,63$ \\
\hline & $\begin{array}{l}\text { Reduction of idle times and control of } \\
\text { the activation sequence }\end{array}$ & $61,62,64,65$ \\
\hline & Optimized process parameters & $\begin{array}{l}{[59,64,66,67,68,69,70,71,72,} \\
73,, 74,\end{array}$ \\
\hline & $\begin{array}{l}\text { Energy and resource efficient process } \\
\text { modeling and planning }\end{array}$ & 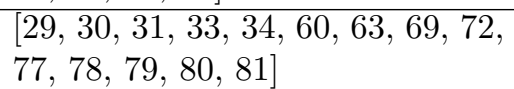 \\
\hline \multirow{2}{*}{$\begin{array}{l}\text { Process/machine } \\
\text { selection }\end{array}$} & Process selection & {$[82,83,84$} \\
\hline & Optimal resource selection & {$[58,85,86,87$} \\
\hline
\end{tabular}

cesses planning and scheduling is studied by Zhang et al. 60. In this work, an integration model based on Nonlinear Process Planning (NLPP) is proposed to select the suitable process planning and scheduling. Thus, the proposed model is used to predict the energy consumption of machine tools, while a genetic algorithm-based approach is adopted to solve the proposed problem. Some of strategies previously discussed and the research topics at line level are summarized and classified in Table 4

At plant level, strategies for improving energy efficiency should consider the use of more efficient technologies and equipment, as well as the monitoring and control systems regarding the energy use in the manufacturing processes and TBS. Nonetheless, most of the optimization methods for energy use proposed so far are focused on both machines and process lines with a specified configuration, while the entire factory with both the technical processes, its auxiliary devices and TBS has not usually been considered. Thus, regarding plant level, the strategies mentioned in this paper are classified into four categories, namely, improvements for the data acquisition, optimal energy design, optimal scheduling by flexible manufacturing systems (regarding energy consumption and peak power), and Smart Manufacturing (SM). This latter category focuses on the trends and new technologies introduced by Industry 4.0 9.

For developing strategies that allow reducing the energy consumption of manufacturing systems from the viewpoint of the whole plant, the primary issue is to understand the energy consumption behavior of the entire plant and its essential elements. However, for achieving a proper knowledge about the consumption behavior of manufacturing systems, data acquisition tools, signal processing techniques, methodologies for processes modeling, and simulation tools are required. In this sense, some works have been developed to treat these concerns and provide better tools that allow acquiring and analyzing the required information. Some other strategies at factory level, such as the production planning and scheduling, load control, demand response, and peak load minimization at factory level have been analyzed as strategies of energy management with the aim of avoiding peak load surcharges and obtaining an appropriate sizing of the infrastructure and the distribution load.

On the other hand, simulation tools are an important research topic since they offer significant improvements for testing system design, models, control strategies, integration of the new system elements, and, in general, allow a better understanding of the manufacturing systems and their dynamics. According to Thiede 28, based on discrete and continuous simulation models, four main simulations paradigms are highlighted, namely, Dynamic Systems Simulation (DSS), System Dynamic Simulation (SDS), Discrete Event Simulation (DES), Agent Based Simulation (ABS), and the integrative application of two or more paradigms (Hybrid Techniques). The former refers to the description of the physical systems behavior by using state variables and algebraic equations in standard tools like Matlab, Python, Octave, among others. SDS is mainly oriented to either ecological or economic models, in which the system is described based on both stock and flows diagrams. In DES, the manufacturing system is modeled as a discrete sequence of events that determine at change in the system state. Each event occurs in a specific time instant and no changes are considered between events 92, 93. In ABS, each object of a defined environment is modeled based on inherent logic and considering the interactions with other objects and the effect over the whole environment [28. In addition to the mentioned simulation approaches, new approaches have been considering for the development of simulations tools, such as Artificial Intelligence (AI) techniques, Petri Nets (PN), and Monte Carlo Simulation (MCS). A detailed explanation of the simulation tools and some applications can be found in [6, 94, 95, 96. In addition, simulation software such as AnyLogic, Arena, and Flexsim, which are based 
Table 4: Research topics to improve energy efficiency at the process line level.

\begin{tabular}{l|l|c}
\hline \multicolumn{1}{c|}{ Approach } & \multicolumn{1}{c}{ Description } & \multicolumn{1}{c}{ Reference } \\
\hline \hline Energy efficient design & $\begin{array}{l}\text { New designs (of machine components and pe- } \\
\text { ripheral devices) based on energy consumption } \\
\text { simulation of whole process line }\end{array}$ \\
\hline $\begin{array}{l}\text { Process planning and } \\
\text { scheduling }\end{array}$ & $\begin{array}{l}\text { Define process plans and machine sequences } \\
\text { for optimal energy consumption }\end{array}$ \\
$\begin{array}{l}\text { Control of peak power de- } \\
\text { mand }\end{array}$ & $\begin{array}{l}\text { Control of process scheduling to avoid peak } \\
\text { load in flexible manufacturing systems }\end{array}$ \\
\hline
\end{tabular}

on the mentioned approaches, have had a great application for the production assembly lines and supply chain in the manufacturing industry.

Currently, the manufacturing industry has had a paradigm shift with the aim to transform the industry into smart factories, fact that confers higher flexibility and sustainability to manufacturing processes. The main promoter of this transformation has been the Industry 4.0 project. Several works have proposed different strategies of modeling, process planning and scheduling, and process design and control for improving the energy efficiency [55, 77, 97. Although many of the reported works consider strategies for flexible manufacturing at the plant level, the energy consumption is usually considered as an initial optimization regarding the production planning of the existing devices in the plant. That is, these strategies determine an optimal sequence from the beginning, and therefore they cannot respond to the temporal variation of processes and working environment factors along the operation of the plant.

Based on the recent advances in sensing technology, connectivity, and computer science, systems in the new era of manufacturing industry have transformed into CPS, which refer to the new generation of systems that integrate computational and physical capabilities, while offering interoperability and resilience 98. Thus, CPS refer to systems that incorporate physical processes and embedded computing elements (e.g., smart sensors and actuators) allowing a real-time interaction, which eases the exchange of information for tasks such as monitoring, control, and management of CPS 98, 99, 100. Regarding connectivity, CPS can set up and use connections with the other systems (including human beings) in global networks for establishing cooperation and collaboration schemes among different systems [99, 101. In Figure 7, a representation scheme of the concept of CPS as systems of systems is presented.

Thus, due to the size, interactions and connections between elements, and the complex dynamics of manufacturing systems, CPS can be regarded as systems of systems that can be implemented at all levels of manufacturing industry (machine, line, plant level), since they represent the physical and embedded computational parts that work in a cooperative way. Then, the implementation of CPS together with Internet of Things (IoT) has fomented the

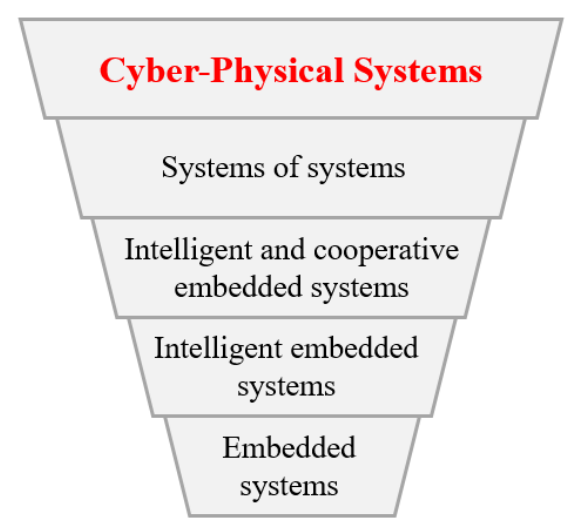

Figure 7: Conceptualization scheme of Cyber-physical systems from systems of systems approach. Taken from 94.

transformation towards the Cyber-Physical Manufacturing Systems (CPMS), which represent the highest level of CPS application in manufacturing industry [100. This fact is given since the connectivity through IoT allows a better knowledge of the manufacturing systems, their energy consumption in real time, and the behavior of supplychain markets related to the industrial activity. In this regard, IoT is considered as an integrated/enabled technology rather than a technology to improve the energy efficiency, which eases the design and implementation in real time of both the energy-efficiency and energy cost reduction control strategies [102. Therefore, based on IoT, a global connection of both the manufacturing systems within an industry and its supply chain can be established in order to consider most of the factors that affect the behavior of a manufacturing plant.

One of the advantages of CPMS integration is the continuous data collection, which might be used to trigger and predict service activities (e.g., routine maintenance activities based on usage or wear, and tear of the equipment), as a way towards energy efficiency improvement in manufacturing systems. Although the implementation of CPMS opens new opportunities to introduce smart technologies in the control systems, the integration of all control resources seen from plant level (e.g., sensors and actuators, the PLC modules, SCADA modules) imposes new challenges for designing management/control strategies of energy demand 
at plant level. Besides, regarding the flexibility and adaptability of manufacturing systems, new strategies that consider a high level of modularity to face any change in either production scheduling or the working environment will be required for the suitable transformation towards SMS.

\section{Control strategies in manufacturing systems}

According to strategies mentioned in the previous section, control techniques have started to gain great application during the last decade in manufacturing systems, mainly due to introduction of smart systems, IoT, and the transformation towards Industry 4.0. Some of potential applications of control systems have focused on both machine and line level since the large scale, and complexity of both systems and relations at plant level. Regarding the machine and line level, the control objectives have been mainly oriented to either processes planning and scheduling to satisfy a production demand, quality of produced pieces by controlling machining processes, and reduction of peak load.

Thus, given the complexity of manufacturing systems due to the processes performed, the strong relations between the peripheral and machining devices, the timevarying constraints such as tool wear, the efficiency of each device (at machine, line, or plant level) and the changingworking environment, the most used control techniques in manufacturing systems are those based on optimization. This fact is given since the control objectives, operating constraints of either devices or machines involved, their operating ranges, dynamic expressions for the relationships between machines and their environment, and any additional constraints that condition the performance of the system to be controlled can be included into an optimization problem.

However, although few control applications consider energy objectives, most of them have been limited to analyze the individual system and do not consider interactions with both other devices and the TBS. In addition, most of these applications consist of designing closed-loop control schemes that minimize the difference between the real energy consumption and a reference behavior, which is usually determined offline and without considering the temporal variations of its surroundings. According to the most relevant reported literature, the energy efficiency objectives usually considered for the design of control systems are focused on 103 :

- Reduction of power peaks: In this case, optimizationbased algorithms aim to reduce the occurrence of peaks produced by simultaneous activation of several devices or machines. Typical objective functions focus on minimize either the infinity norm of the power signal along a fixed period (e.g., a machine cycle) or the sum of penalties for the instantaneous power values that surpass a threshold value corresponding to a nominal power purchased.
- Load-profile smoothing: In this case, the optimizationbased algorithms search smoothing the global power consumption profile by minimizing the difference between the instantaneous power consumption and the mean load demand of the machine tool during its operation. Although this approach allows obtaining smooth profiles, in some cases it implicates higher total energy demand when the instantaneous power will be lower than its mean value.

- Load reduction: From this approach, significantly cost reductions could be achieved since, in this case, optimization-based algorithms are oriented to minimize the total load demand. Most of the proposed cost functions to achieve this objective consist of minimizing the area under the curve of the total power consumption profile. On the other hand, for those cases in which some peripheral devices can be managed in real time, a possible control objective is to minimize the difference between the global energy consumption and the fixed power from unmanaged devices in the machine.

Thus, based on the works related to the design of control strategies, these control objectives have been of high priority since they take into account the way in which the electric companies sell energy to the manufacturing industries. Moreover, from these objectives, the energy costs could be minimized in the facility without modifying either the physical structure of the plant or the current design of devices. Some applications of these control objectives in the design of control strategies are presented in Tables 3 and 4 into the approaches named optimized process control, process planning and scheduling, and control of power-peak demand.

Additional to the objectives previously mentioned, their suitable combinations, technical constraints and algorithms to solve optimization problems would be considered, e.g., technical constraints referred to limitations of running and idle times for devices, switching frequency, a time interval for switching on devices, among others [103. However, although these approaches have had a great application for designing control systems oriented to both energy efficiency and process planning and scheduling, in most of the case studies disturbances or changes in the working environment conditions are not considered. Therefore, and taking into account the current context of manufacturing industry and the introduction of SM and Industry 4.0, strategies able to respond in real time to any changes in the system or its environment, besides to consider flexibility in the processes plan and schedule should be developed [61].

According to the U.S. National Institute of Standards and Technology (NIST), SM is defined as "fully-integrated and collaborative manufacturing systems that respond in real time to meet the changing demands and conditions in the factory, supply network, and customer needs" [104]. 
Thus, SM can be understood as a collection of innovative technologies that can respond to complex changes in manufacturing systems in real time, promoting the decision making in real time through the introduction of Information and Communications Technologies (ICT), and the interaction among humans, technology, and information. Among the most well-known techniques to promote the transformation towards SM, Kang et al. 104 highlight the cloud computing, IoT, CPS, and big data. CPS have been recognized as useful tools for shifting of pyramid automation towards locally controlled modules without hierarchy, as show in Figure 8. Thus, one of the advantages of CPSbased automation is that it allow companies a highly degree of shared information at all levels, from which control systems could respond quickly on the appropriate level.

In this sense, from the developments in sensing technologies, the improvements in data acquisition and signal processing techniques, in the new era of SM industry a lot information is available to be used in pro of monitoring and controlling these systems. Therefore, during the last years more robust control systems able to treat and use the available information have been developed. For example, currently, control systems oriented to prognosis and maintenance of manufacturing systems, based on the historical data, have been developed with the aim to predict and program the required changes or maintenance activities [107, 108, 109]. Additional to the prediction of maintenance tasks, strategies such as receding horizon control and advanced methods of process control (e.g., model predictive control (MPC)), have started to gain attention too, mainly, focusing on problems of energy efficiency and flexibility for planning and scheduling of processes at machine, line, and plant level [110, 111, 112, 113.

Due to the periodic behavior of the machine tools, these control strategies had not had a great application since an optimal activation sequence for both peripheral and machining devices was determined off-line for the nominal operation of machines. Nonetheless, nowadays, it is considered that peripheral devices can be independently managed from machining devices in pro of energy efficiency and without to compromise the machining operation, since these devices could or could not have a periodic behavior. Based on this fact, application of MPC controllers for selective on/off switching of these devices, based on their own dynamic behavior and the total energy consumption of the machine have gained interest as a control strategy oriented to improve the energy efficiency of manufacturing systems [114, 110, 115.

As a consequence, most of the approaches addressed and related to the design of control systems at the machine level aim for the selective actuation of non-continuouslyrequired devices, the reduction of the idle times, and improvements in the process planning and modeling for their application in advanced control systems. In this sense, Frigerio and Matta 62 present an optimal switch-off policy for the energy consumption control of machine tools in a manufacturing industry, considering time-dependent warm-up duration and the random arrival of parts to the machine. This policy is based on the idea that, once the manufacturing of a part is finished, the machine remains in on-service status only for a short time, but if it passes a defined time interval $\tau$ without the entry of a new part, the machine will be switched off.

On the other hand, Shrouf et al. 63 propose a mathematical model of energy consumption considering only three operational modes (processing, idle, and shut down) for a machine, with the aim to minimize the total energy consumption of single-machine scheduling taking into account the continuous changes in energy prices. The general idea of this work is to provide a tool that helps to choose the most efficient production schedule for a individual machine, which could be useful like a reference or set-point for a control strategy. Thus, for designing advanced control systems based on optimization, additional to available information, models of the electrical energy consumption of manufacturing systems that will be simple and precise enough to solve on-line the optimization problem with small computing times are required. In this sense, the need of methodologies for correctly modeling both energy consumption of manufacturing systems and the dynamic relations with other devices and its environment, in addition of integrating the available information from real processes, is highlighted.

In the same way, the control of peak power demand has been another research focus to improve the energy efficiency of manufacturing systems at process line level. Sun et al. 90. propose an advanced buffer inventory management method to reduce the electricity consumption during peak periods of a multi-machine system and buffers. Moreover, Suwa and Samukawa 91] introduce the concepts of a processing mode and electric energy capacity plan for optimizing the energy efficiency of processes in a flexible manufacturing system with several machine tools. In this sense, most of the strategies currently implemented regarding the peak power control consist of delaying the switching-on of some machines taking into account a threshold value. Usually, this last value corresponds to the contracted nominal power, which produces economic penalties if it is exceeded.

At the plant level, in which there exist more complex relations and large-scale system schemes are considered, some of the main research topics for designing control strategies are focus on understanding the energy consumption of systems seen from this level. In this sense, Stich et al. [1] introduce a conceptual framework for energy efficiency based on an Event-Driven Architecture (EDA) and Complex-Event-Processing (CEP) with the aim to provide detailed information about the energy deviations of factory targets that can be useful for the production planning and control of manufacturing systems. In the same way, Krones and Müller [116] have proposed an approach for reducing energy consumption by providing a selection method of the more appropriate energy efficiency measures to be used by factory planning participants, with the aim to overcome the high efforts to acquire energy data. Thus, 

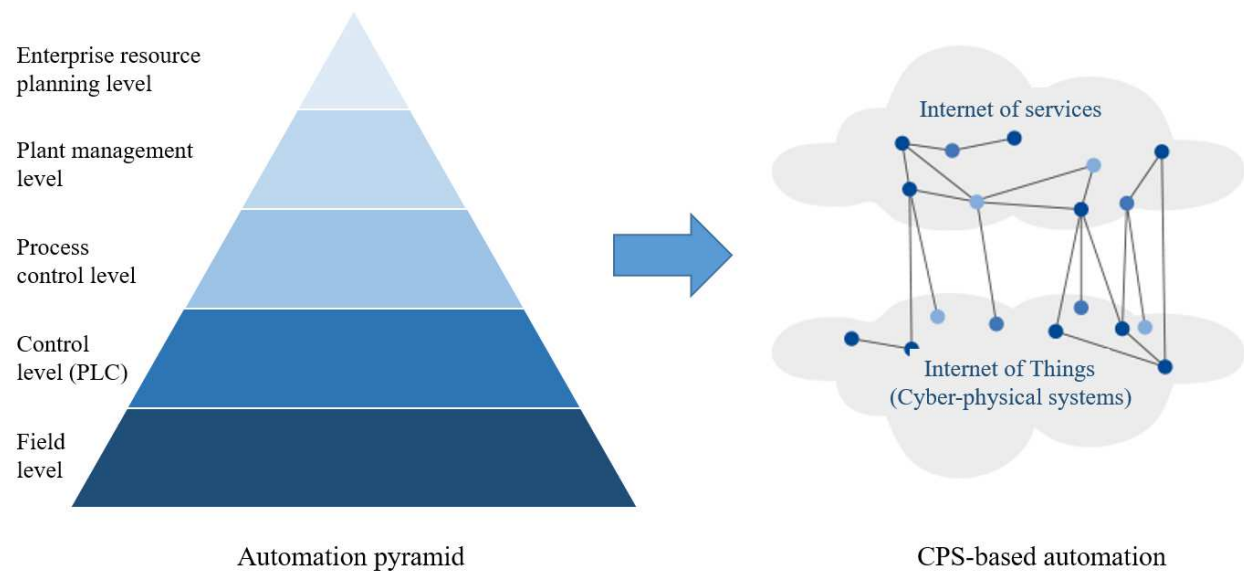

CPS-based automation

Figure 8: Transformation of automation structure by introducing the CPS concept. Based on [105] 106].

with the aim to integrate control strategies at the plant level with both the available information from processes and the new technologies considered by Industry 4.0 (SM, IoT, etc.), some works have been proposed mainly focusing on data acquisition, and data analysis and processing regarding processes performance and energy demand.

At highest levels, just a few of the control strategies implemented are directly related to the energy efficiency of manufacturing systems. In the work of Tan et al. [102, the problem of lack the real-time visibility of energy efficiency on the shop floor is treated. In this work, an IoT enabled software application for real-time monitoring of the energy efficiency of manufacturing factories, together with a data envelopment analysis technique to detect abnormal energy consumption patterns and quantify energy efficiency gaps is developed. This work shows a clear example of utility and application of the available technologies in Industry 4.0, from which it is possible to access the energy information and efficiently analyzing it to extract key performance indicators that can be used as helpful tools in the energy management/control. Following the same way towards the energy efficiency, the work proposed by Zou et al. 114 present a novel strategy for controlling the energy consumption of manufacturing systems. In this work, a data-driven stochastic manufacturing systems modeling method is proposed to achieve a predicting system that will be used later to design control systems. Then, from the obtained results, a real-time distributed feedback production control policy that integrates the current and predicted system performance to improve the overall profit and energy efficiency is presented.

Thus, the integration of both concept of the CPMS, IoT, and advances in sensing technologies, among other such that is show in Figure 9, promotes the design of advanced control strategies into the context of SM and Industry 4.0, which can be implemented in real time with computing times small enough to solve the optimization problem, determine the optimal control actions, and exe-

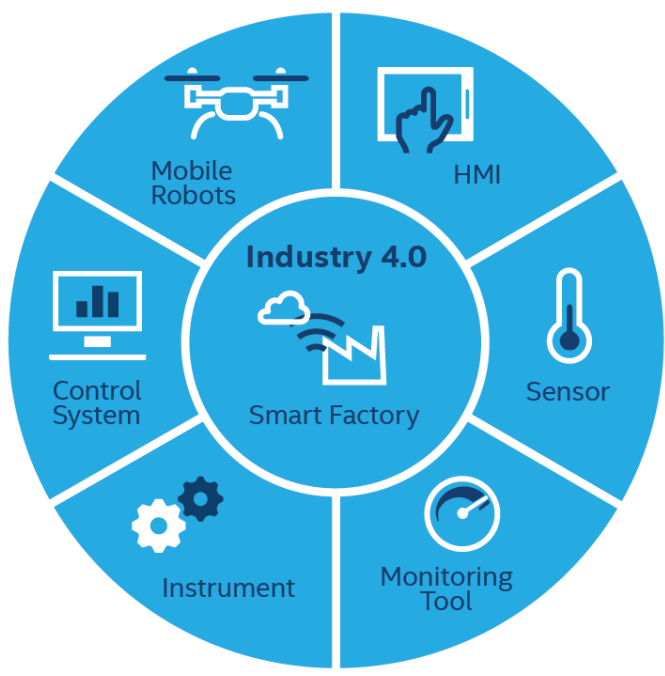

Figure 9: Integration architecture of fostering technologies of smart factories. Taken from [117.

cute the corresponding actions to keep the system in the desired state (i.e., the set-point). In this sense, the application of these technologies towards a more sustainable and flexible manufacturing industry, for instance, by reducing resources consumption (e.g. electrical energy) and custom services, promote and challenge, at the same time, the design of control systems robust enough to treat the complexity, large scale, and coupling of manufacturing systems at each levels (e.g., machine, line, and plant) and to establish communication scheme among different levels.

The integration of CPMS and IoT into the manufacturing systems towards Industry 4.0 requires the suitable synergy of several scientific and technological fields. Since the result of such interaction can yield in complex systems of systems, new challenges naturally arise in the technological dimension for the development of suitable architectures that support these systems. Thus, from a tech- 
nical point of view, the embedded systems, sensor technology, actuation technology, decentralized data processing capacities (microcontroller), centralized data processing capacities (big data), communication interfaces (Ethernet, Wi-Fi, RFID, GPS, NFC, etc.), and communication protocols (IPv6, OPC UA, etc.) are required to the successful integration of CPMS and IoT into manufacturing systems 118. Based on these approaches, systems can be transformed into smart entities with a defined identity, sensing capabilities of physical processes, actuation mechanisms, data processing ability and connectivity through network interfaces. Therefore, a digitization stage of information collected about the physical conditions in the plant is required. Due to this fact, an important factor is the installation of suitable sensors to cover the operating ranges of the process and with the expected precision. Into the context of Industry 4.0, sensors should have the features of durability, robustness, reliability, non-invasive installations, self-power, and wireless transmission [119. For instance, regarding energy consumption, the sensors commonly used by manufacturing industries are wireless current and voltage sensors. In addition, some industries integrate vibration sensors in order to analyze and predict possible equipment malfunctions, which increase their energy consumption. From these sensors is possible monitoring the phase-phase voltage, phase to neutral voltage, phase current, frequency, active power, reactive power, apparent power, active energy, reactive energy, power factor, instantaneous demand amps, instantaneous demand active power, instantaneous demand apparent power, maximum demand active power and maximum demand apparent power [120, 121.

Afterward, the collected data need to be processed, analyzed, and integrated to make decisions by using suitable communications platforms and protocols. In this regard, IoT is widely used to describe embedded systems through Internet connectivity in order to allow the interaction with other systems, human, or services, on a global scale [122, 118. According to Mukhopadhyay [122], IoT can increase reliability, sustainability, and efficiency by improved access to information. However, to provide Internet to the whole facility is a high investment that should be carefully analyzed. This fact has carried out that opponents to IoT started to question and critice the return of investment (ROI) of the IoT implementation in manufacturing industry. Following these critical voices, some researches have focused on analyzing the real value of IoT integration in terms of time, flexibility, reliability, cost, and quality. In [118, different contributions regarding these issues are presented. The ROI is defined in a general way as the ratio of the net gain to the costs of investment, but regarding IoT investment the hidden benefices may provide critical evidence in favor of IoT. In [123, a practical approach to calculate the return on investment for IoT is presented. Besides, it should be noted that in accordance with the 2017 Roundup of Internet of Things Forecasts by FORBES, "the majority of enterprises adopting IoT to- day are using metrics and key performance indicators that reflect operational improvements, customer experience, logistics, and supply chain gains". In addition, the global IoT market will grow from $\$ 157 \mathrm{~B}$ in 2016 to $\$ 457 \mathrm{~B}$ by 2020 , with manufacturing industry as one of the lead industries in IoT spending [124.

\section{Conclussions and trends}

The current context of energy efficiency in manufacturing systems and applied control strategies have been introduced and discussed aiming to identify the driver technologies for reducing the energy consumption and improving both energy efficiency and sustainability of these systems. Due to the large scale of manufacturing systems and their complexity, an approach by levels has been addressed allowing a better comprehension of their fundamental components and relationships. The first level considered was the machine, in which the manufacturing processes performed and the peripheral devices are included. This level corresponds to the basic unit in the parts manufacturing, and therefore a discussion about its operating modes, its energy consumption behavior, the primary energy consumers, and classification of consumed energy into fixed and variable was presented.

Then, when interactions among machines in the same arrangement are considered, the second level (or process line) is defined. This level corresponds to an arrangement of machines, each one developing a defined operation and organized in a fixed sequence towards the production of a finished part. In the same way as machine level at process line level, there are peripheral elements that could work for one machine or a set of them, from which more complex interactions appear and must be considered to improve the energy efficiency. The third level addressed here is the factory or plant level, which is an extension of the previous levels and their complex interactions at each level and among them but which included the interactions of all manufacturing systems with the technical building services and the rest of activities of a factory. Thus, according to the approach by levels and the reported literature regarding the current context of energy efficiency of manufacturing systems, the following remarks can be made:

- At machine level, improvements related to more efficient machine components from new designs or the use of materials with better mechanical properties have been proposed. On the other hand, regarding manufacturing processes performed in a machine, strategies to optimize the machining parameters and to obtain an improve processes planning for the production of a part considering the energy consumption have been performed. However, although most of the discussed proposals highlight significant improvements in reducing the energy consumption of a machine, they could 
be non-realistic in a real case in which a machine interacts and is affected with/by other machines and the environment. Therefore, efforts that not only consider a machine as an isolated entity should be performed but also including uncertainty and perturbations mainly for the scenarios in which it is desired to improve the processes planning in a machine. In the same way that these factors will be included to propose improvements in energy efficiency, tools that face changes in real time are required, mainly for the external factors in a real working environment and for the flexibility required by new the SM framework.

- In the process line level, improved tools focusing on the modeling, monitoring and control the total energy consumption are required more and more. Although better modeling processes have been proposed, they can be quite restrictive and could not be generalizable in the current context of flexible and reconfigurable manufacturing. Thus, improvements regarding modeling of the modularity of manufacturing processes, which can be scalable to line level, are required for their use in monitoring and control systems. In the same way, the ICT, IoT, CPS, and advances in sensing technology should be taken into account for proposing more robust control systems able to respond in real time to internal and external factors without to compromise the energy and production efficiency.

- At plant level, new approaches for the integration and synergy among the strategies at lower levels are required. Most of the proposed strategies in the literature have been focused on flexibility and the inclusion of advanced technologies in the process planning and scheduling but restricted to an initial optimization. Therefore, to increase the energy efficiency of the manufacturing systems, both energy consumption reduction and better use of resources are key factors to be improved for achieving a sustainable development from all dimensions: economic, environmental, and social. In this sense, strategies to improve the control and management of the energy and all resources in a manufacturing plant are required, fact that has motivated the development of technologies previously discussed and mathematical tools proper to solve the optimization problems at plant level. Thus, due to the complexity and size of systems at plant level, efficient tools for solving the optimization problems in short time are required, with the aim that the control and management strategies can be implemented in real time. On the other hand, regarding the energy inputs to a factory, the issues associated with renewable sources and efficient ways to supply the energy by the power grid should be considered.

Finally, at any level analyzed, improvements regarding data acquisition and processing techniques of the raw data are required if the new developments in sensing technology and the new CPS want to be included in the monitoring and control systems. Therefore, the inclusion of new technologies imposes challenges to the design of control systems, not only due to the complexity of these systems but also the requirements of computing time. Thereby, management/control systems should be able to predict the energy consumption behavior of manufacturing systems, determine control actions and perform the changes in reasonable time for their implementation in real time. In this sense, and taking into account the needed elements towards the design of control systems (e.g., the system model, solver, control structure, etc.), improvements in each one of their elements are required.

\section{References}

[1] V. Stich, N. Hering, C. Starick, U. Brandenburg, EnergyEfficiency Concept for the Manufacturing Industry, in: V. Prabhu, M. Taisch, D. Kiritsis (Eds.), Advances in Production Management Systems. Sustainable Production and Service Supply Chains, Springer Berlin Heidelberg, Berlin, Heidelberg, ISBN 978-3-642-41266-0, 86-93, 2013.

[2] Z. Zhou, B. Yao, W. Xu, L. Wang, Condition monitoring towards energy-efficient manufacturing: a review, The International Journal of Advanced Manufacturing Technology 91 (912) (2017) 3395-3415, doi:10.1007/s00170-017-0014-x

[3] IEA, International Energy Agency: World Energy Statistics 2017, urlhttp://www.iea.org/statistics/, 2018.

[4] A. Fathima, K. Palanisamy, Optimization in microgrids with hybrid energy systems - A review, Renewable and Sustainable Energy Reviews 45 (2015) 431-446, ISSN 1364-0321, doi:10. 1016/j.rser.2015.01.059

[5] J. Leithon, S. Werner, V. Koivunen, Renewable Energy Optimization with Centralized and Distributed Generation, in: 2018 26th European Signal Processing Conference (EUSIPCO), ISSN 2076-1465, 181-185, doi:10.23919/EUSIPCO. $2018.8553323,2018$.

[6] M. Khan, J. Wang, M. Ma, L. Xiong, P. Li, F. Wu, Optimal energy management and control aspects of distributed microgrid using multi-agent systems, Sustainable Cities and Society 44 (2019) 855 870, ISSN 2210-6707, doi:10.1016/j.scs.2018.11.009

[7] S. Bilgen, Structure and environmental impact of global energy consumption, Renewable and Sustainable Energy Reviews 38 (2014) 890-902, doi:10.1016/j.rser.2014.07.004

[8] G. Ingarao, Manufacturing strategies for efficiency in energy and resources use: The role of metal shaping processes, Journal of Cleaner Production 142 (2017) 2872 - 2886, ISSN 0959-6526, doi:10.1016/j.jclepro.2016.10.182

[9] Z. Jakovljevic, V. Majstorovic, S. Stojadinovic, S. Zivkovic, N. Gligorijevic, M. Pajic, Cyber-Physical Manufacturing Systems (CPMS), in: V. Majstorovic, Z. Jakovljevic (Eds.), Proceedings of 5th International Conference on Advanced Manufacturing Engineering and Technologies, Springer International Publishing, Cham, ISBN 978-3-319-56430-2, 199-214, 2017.

[10] J. R. Duflou, J. W. Sutherland, D. Dornfeld, C. Herrmann, J. Jeswiet, S. Kara, M. Hauschild, K. Kellens, Towards energy and resource efficient manufacturing: A processes and systems approach, CIRP Annals - Manufacturing Technology 61 (2) (2012) 587-609, doi:10.1016/j.cirp.2012.05.002

[11] A. Trianni, E. Cagno, S. Farné, Barriers, drivers and decisionmaking process for industrial energy efficiency: A broad study among manufacturing small and medium-sized enterprises, Applied Energy 162 (2016) 1537-1551, ISSN 0306-2619, doi: 10.1016/j.apenergy.2015.02.078

[12] G. May, B. Stahl, M. Taisch, D. Kiritsis, Energy management in manufacturing: From literature review to a conceptual 
framework, Journal of Cleaner Production 167 (2017) 14641489, doi:10.1016/j.jclepro.2016.10.191

[13] X. Xia, L. Zhang, Industrial energy systems in view of energy efficiency and operation control, Annual Reviews in Control 42 (2016) 299-308, ISSN 1367-5788, doi:10.1016/j.arcontrol.2016. 09.009

[14] Z. Yingjie, Energy efficiency techniques in machining process: a review, The International Journal of Advanced Manufacturing Technology 71 (5-8) (2013) 1123-1132, doi:10.1007/ s00170-013-5551-3

[15] F. Apostolos, P. Alexios, P. Georgios, S. Panagiotis, C. George, Energy Efficiency of Manufacturing Processes: A Critical Review, Procedia CIRP 7 (2013) 628-633, doi:10.1016/j.procir. 2013.06.044

[16] B. Esmaeilian, S. Behdad, B. Wang, The evolution and future of manufacturing: A review, Journal of Manufacturing Systems 39 (2016) 79-100, doi:10.1016/j.jmsy.2016.03.001

[17] A. Zein, Energy Demand of Machine Tools and Performance Management, in: Transition Towards Energy Efficient Machine Tools, Springer Berlin Heidelberg, 5-36, doi:10.1007/ 978-3-642-32247-1_2, 2012.

[18] R. Yin, Metallurgical process engineering, Metallurgical Industry Press Springer, Beijing Berlin, ISBN 978-3-642-13956-7, 2011.

[19] A. Nassehi, S. Newman, V. Dhokia, Z. Zhu, R. I. Asrai, Using formal methods to model hybrid manufacturing processes, Enabling Manufacturing Competitiveness and Economic Sustainability (2012) 52-56 doi:10.1007/978-3-642-23860-4_8

[20] K. Stouffer, V. Pillitteri, S. Lightman, M. Abrams, A. Hahn, Guide to Industrial Control Systems (ICS) Security, Tech. Rep., doi:10.6028/nist.sp.800-82r2, 2015.

[21] M. U. Uluer, H. O. Unver, G. Gok, N. Fescioglu-Unver, S. E. Kilic, A framework for energy reduction in manufacturing process chains (E-MPC) and a case study from the Turkish household appliance industry, Journal of Cleaner Production 112 (2016) 3342-3360, doi:10.1016/j.jclepro.2015.09.106

[22] P. Butala, K. Mpofu, Assembly Systems, Springer Berlin Heidelberg, Berlin, Heidelberg, ISBN 978-3-642-35950-7, 1-5, doi: 10.1007/978-3-642-35950-7_16789-1, 2014

[23] T. Aized, Material Handling in Flexible Manufacturing System, InTech, ISBN 978-953-307-128-2, 2010.

[24] K. J. Roodbergen, I. F. Vis, A survey of literature on automated storage and retrieval systems, European Journal of Operational Research 194 (2) (2009) 343-362, ISSN 0377-2217, doi:10.1016/j.ejor.2008.01.038

[25] C. Herrmann, S. Thiede, Process chain simulation to foster energy efficiency in manufacturing, CIRP Journal of Manufacturing Science and Technology 1 (4) (2009) 221-229, doi: 10.1016/j.cirpj.2009.06.005

[26] K. Salonitis, P. Ball, Energy Efficient Manufacturing from Machine Tools to Manufacturing Systems, Procedia CIRP 7 (2013) 634-639, doi:10.1016/j.procir.2013.06.045.

[27] C. Reich-Weiser, A. Vijayaraghavan, D. Dornfeld, Appropriate use of green manufacturing frameworks, Laboratory for Manufacturing and Sustainability

[28] S. Thiede, Theoretical Background, Springer Berlin Heidelberg, Berlin, Heidelberg, ISBN 978-3-642-25914-2, 9-34, doi: 10.1007/978-3-642-25914-2_2. 2012.

[29] T. Schudeleit, S. Züst, L. Weiss, K. Wegener, The Total Energy Efficiency Index for machine tools, Energy 102 (Supplement C) (2016) 682-693, ISSN 0360-5442, doi:10.1016/j.energy.2016.02. 126

[30] S. Hu, F. Liu, Y. He, T. Hu, An on-line approach for energy efficiency monitoring of machine tools, Journal of Cleaner Production 27 (Supplement C) (2012) 133-140, ISSN 0959-6526, doi:10.1016/j.jclepro.2012.01.013

[31] L. Zhou, J. Li, F. Li, Q. Meng, J. Li, X. Xu, Energy consumption model and energy efficiency of machine tools: a comprehensive literature review, Journal of Cleaner Production 112 (Part 5) (2016) 3721-3734, ISSN 0959-6526, doi: 10.1016/j.jclepro.2015.05.093
[32] G. Mert, S. Waltemode, J. Aurich, How Services Influence the Energy Efficiency of Machine Tools: A Case Study of a Machine Tool Manufacturer, Procedia CIRP 29 (2015) 287-292, ISSN 2212-8271, doi:10.1016/j.procir.2015.01.022 the 22nd CIRP Conference on Life Cycle Engineering.

[33] A. Gontarz, S. Zust, L. Weiss, K. Wegener, Energetic machine tool modeling approach for energy consumption prediction, in: Proceedings of the GCSM 2012 10th Global Conference on Sustainable Manufacturing, ETH Zurich, doi: 10.3929/ethz-a-007577766 2012

[34] G. Zhao, Z. Liu, Y. He, H. Cao, Y. Guo, Energy consumption in machining: Classification, prediction, and reduction strategy, Energy 133 (2017) 142-157, doi:10.1016/j.energy.2017.05. 110

[35] H. A. ElMaraghy, A. M. Youssef, A. M. Marzouk, W. H. ElMaraghy, Energy use analysis and local benchmarking of manufacturing lines, Journal of Cleaner Production 163 (2017) 3648, doi:10.1016/j.jclepro.2015.12.026

[36] S. Wahren, E. Colangelo, A. Sauer, J. Mandel, J. Siegert, Keeping a Factory in an Energy-optimal State, Procedia CIRP 40 (2016) 50-55, ISSN 2212-8271, doi:10.1016/j.procir.2016.01. 053 13th Global Conference on Sustainable Manufacturing Decoupling Growth from Resource Use.

[37] M. Fahad, S. A. A. Naqvi, M. Atir, M. Zubair, M. M. Shehzad, Energy Management in a Manufacturing Industry through Layout Design, Procedia Manufacturing 8 (October 2016) (2017) 168-174, ISSN 23519789, doi:10.1016/j.promfg. 2017.02.020

[38] C.-W. Park, K.-S. Kwon, W.-B. Kim, B.-K. Min, S.-J. Park, I.-H. Sung, Y. S. Yoon, K.-S. Lee, J.-H. Lee, J. Seok, Energy consumption reduction technology in manufacturing A selective review of policies, standards, and research, International Journal of Precision Engineering and Manufacturing 10 (5) (2009) 151-173, doi:10.1007/s12541-009-0107-z

[39] S. Züst, R. Züst, T. Schudeleit, K. Wegener, Development and Application of an Eco-design Tool for Machine Tools, Procedia CIRP 48 (2016) 431-436, ISSN 22128271, doi:10.1016/j.procir. 2016.03.032

[40] Q. Zhu, F. Lujia, A. Mayyas, M. Omar, Y. Al-Hammadi, S. A. Saleh, Production energy optimization using low dynamic programming, a decision support tool for sustainable manufacturing, Journal of Cleaner Production 105 (2015) 178 - 183, ISSN 0959-6526, doi:10.1016/j.jclepro.2014.02.066

[41] M. Omar, Z. Qilun, F. Lujia, A. A. Ali, D. Lahjouji, M. Khraisheh, A hybrid simulation approach for predicting energy flows in production lines, International Journal of Sustainable Engineering 9 (1) (2016) 25-34, doi:10.1080/19397038. 2015.1008599

[42] G. Bogdanski, T. Spiering, W. Li, C. Herrmann, S. Kara, Energy Monitoring in Manufacturing Companies - Generating Energy Awareness through Feedback, Springer, Berlin, Heidelberg, ISBN 978-3-642-29069-5, 539-544, doi:10.1007/ 978-3-642-29069-5_91, 2012.

[43] ISO-50006:2014, Energy management systems — Measuring energy performance using energy baselines $(\mathrm{EnB})$ and energy performance indicators (EnPI) - General principles and guidance, Tech. Rep., International Organization for Standardization (ISO), 2014.

[44] H.-S. Yoon, E.-S. Kim, M.-S. Kim, J.-Y. Lee, G.-B. Lee, S.H. Ahn, Towards greener machine tools - A review on energy saving strategies and technologies, Renewable and Sustainable Energy Reviews 48 (2015) 870-891, doi:10.1016/j.rser.2015.03. 100

[45] W. Li, S. Kara, An empirical model for predicting energy consumption of manufacturing processes: a case of turning process, Proceedings of the Institution of Mechanical Engineers, Part B: Journal of Engineering Manufacture 225 (9) (2011) 1636-1646, doi:10.1177/2041297511398541

[46] L. Li, J. Yan, Z. Xing, Energy requirements evaluation of milling machines based on thermal equilibrium and empirical modelling, Journal of Cleaner Production 52 (Supplement C) 
(2013) 113-121, ISSN 0959-6526, doi:10.1016/j.jclepro.2013. 02.039

[47] K. Bunse, M. Vodicka, P. Schönsleben, M. Brülhart, F. Ernst, Integrating energy efficiency performance in production management - gap analysis between industrial needs and scientific literature, Journal of Cleaner Production 19 (6) (2011) 667679, ISSN 0959-6526, doi:10.1016/j.jclepro.2010.11.011.

[48] C. Schmidt, W. Li, S. Thiede, B. Kornfeld, S. Kara, C. Herrmann, Implementing Key Performance Indicators for Energy Efficiency in Manufacturing, Procedia CIRP 57 (2016) 758763, ISSN 2212-8271, doi:10.1016/j.procir.2016.11.131 factories of the Future in the digital environment - Proceedings of the 49th CIRP Conference on Manufacturing Systems.

[49] J.-C. Brunke, M. Johansson, P. Thollander, Empirical investigation of barriers and drivers to the adoption of energy conservation measures, energy management practices and energy services in the Swedish iron and steel industry, Journal of Cleaner Production 84 (2014) 509-525, ISSN 0959-6526, doi: 10.1016/j.jclepro.2014.04.078

[50] E. Cagno, A. Trianni, Exploring drivers for energy efficiency within small- and medium-sized enterprises: First evidences from Italian manufacturing enterprises, Applied Energy 104 (2013) 276-285, ISSN 0306-2619, doi:10.1016/j.apenergy.2012. 10.053

[51] E. Cagno, A. Trianni, Evaluating the barriers to specific industrial energy efficiency measures: an exploratory study in small and medium-sized enterprises, Journal of Cleaner Production 82 (2014) 70-83, ISSN 0959-6526, doi:10.1016/j.jclepro.2014. 06.057 .

[52] A. Gontarz, T. Schudeleit, K. Wegener, Framework of a Machine Tool Configurator for Energy Efficiency, Procedia CIRP 26 (2015) 706-711, ISSN 2212-8271, doi:10.1016/j.procir.2014. 07.185

[53] D. Fratila, Macro-level environmental comparison of near-dry machining and flood machining, Journal of Cleaner Production 18 (10) (2010) 1031-1039, ISSN 0959-6526, doi:10.1016/j. jclepro.2010.01.017

[54] S. A. Tadavani, R. S. Razavi, R. Vafaei, Pulsed laser-assisted machining of Inconel 718 superalloy, Optics \& Laser Technology 87 (2017) 72-78, ISSN 0030-3992, doi:10.1016/j.optlastec. 2016.07.020

[55] L. Shabi, J. Weber, J. Weber, Analysis of the Energy Consumption of Fluidic Systems in Machine Tools, Procedia CIRP 63 (2017) 573-579, ISSN 2212-8271, doi:10.1016/j.procir.2017. 03.348 manufacturing Systems 4.0 - Proceedings of the 50th CIRP Conference on Manufacturing Systems.

[56] R. Wiedenmann, M. F. Zaeh, Laser-assisted milling-Process modeling and experimental validation, CIRP Journal of Manufacturing Science and Technology 8 (2015) 70-77, ISSN 17555817, doi:10.1016/j.cirpj.2014.08.003

[57] N. Diaz, S. Choi, M. Helu, Y. Chen, S. Jayanathan, Y. Yasui, D. Kong, S. Pavanaskar, D. Dornfeld, Machine tool design and operation strategies for green manufacturing, Laboratory for Manufacturing and Sustainability .

[58] E. Benedicto, D. Carou, E. Rubio, Technical, Economic and Environmental Review of the Lubrication/Cooling Systems Used in Machining Processes, Procedia Engineering 184 (2017) 99-116, ISSN 1877-7058, doi:10.1016/j.proeng.2017.04. 075 advances in Material \& Processing Technologies Conference.

[59] L. Li, C. Li, Y. Tang, L. Li, An integrated approach of process planning and cutting parameter optimization for energy-aware CNC machining, Journal of Cleaner Production 162 (2017) 458-473, ISSN 0959-6526, doi:10.1016/j.jclepro.2017.06.034

[60] Z. Zhang, . Tang, T. Peng, L. Tao, S. Jia, A method for minimizing the energy consumption of machining system: integration of process planning and scheduling, Journal of Cleaner Production 137 (2016) 1647-1662, ISSN 0959-6526, doi:10.1016/j.jclepro.2016.03.101

[61] E. Abele, N. Panten, B. Menz, Data Collection for Energy Monitoring Purposes and Energy Control of Production Ma- chines, Procedia CIRP 29 (2015) 299-304, ISSN 2212-8271, doi:10.1016/j.procir.2015.01.035 the 22nd CIRP Conference on Life Cycle Engineering.

[62] N. Frigerio, A. Matta, Energy Efficient Control Strategy for Machine Tools with Stochastic Arrivals and Time Dependent Warm-up, Procedia CIRP 15 (2014) 56-61, ISSN 22128271, doi:10.1016/j.procir.2014.06.040 21st CIRP Conference on Life Cycle Engineering.

[63] F. Shrouf, J. Ordieres-Meré, A. García-Sánchez, M. OrtegaMier, Optimizing the production scheduling of a single machine to minimize total energy consumption costs, Journal of Cleaner Production 67 (2014) 197-207, ISSN 0959-6526, doi: 10.1016/j.jclepro.2013.12.024

[64] O. Velásquez, D. Kim, D. Y. Lee, M. A. Suhaimi, Trade-off analysis between machining time and energy consumption in impeller NC machining, Robotics and Computer-Integrated Manufacturing 43 (2017) 164-170, ISSN 0736-5845, doi:10. 1016/j.rcim.2015.09.014, special Issue: Extended Papers Selected from FAIM 2014.

[65] P. Eberspächera, A. Verla, Realizing Energy Reduction of Machine Tools Through a Control-integrated Consumption Graph-based Optimization Method, Procedia CIRP 7 (2013) 640-645, ISSN 2212-8271, doi:10.1016/j.procir.2013.06.046 forty Sixth CIRP Conference on Manufacturing Systems 2013.

[66] W. Lee, S. H. Kim, J. Park, B. Min, Simulation-based machining condition optimization for machine tool energy consumption reduction, Journal of Cleaner Production 150 (2017) 352-360, ISSN 0959-6526, doi:10.1016/j.jclepro.2017.02.178

[67] Q. Zhong, R. Tang, T. Peng, Decision rules for energy consumption minimization during material removal process in turning, Journal of Cleaner Production 140 (2017) 1819-1827, ISSN 0959-6526, doi:10.1016/j.jclepro.2016.07.084

[68] J. Lv, R. Tang, W. Tang, Y. Liu, Y. Zhang, S. Jia, An investigation into reducing the spindle acceleration energy consumption of machine tools, Journal of Cleaner Production 143 (2017) 794-803, ISSN 0959-6526, doi:10.1016/j.jclepro.2016. 12.045

[69] Z. Deng, H. Zhang, Y. Fu, L. Wan, W. Liu, Optimization of process parameters for minimum energy consumption based on cutting specific energy consumption, Journal of Cleaner Production 166 (2017) 1407-1414, ISSN 0959-6526, doi:10.1016/j.jclepro.2017.08.022

[70] Y. Zhang, J. Wang, Y. Liu, Game theory based real-time multiobjective flexible job shop scheduling considering environmental impact, Journal of Cleaner Production 167 (2017) 665-679, ISSN 0959-6526, doi:10.1016/j.jclepro.2017.08.068

[71] L. Li, X. Deng, J. Zhao, F. Zhao, J. W. Sutherland, Multi-objective optimization of tool path considering efficiency, energy-saving and carbon-emission for free-form surface milling, Journal of Cleaner Production 172 (2018) 3311-3322, ISSN 0959-6526, doi:10.1016/j.jclepro.2017.07.219

[72] J. Yan, L. Li, F. Zhao, F. Zhang, Q. Zhao, A multi-level optimization approach for energy-efficient flexible flow shop scheduling, Journal of Cleaner Production 137 (2016) 15431552, ISSN 0959-6526, doi:10.1016/j.jclepro.2016.06.161

[73] G. Kant, K. S. Sangwan, Prediction and optimization of machining parameters for minimizing power consumption and surface roughness in machining, Journal of Cleaner Production 83 (2014) 151-164, ISSN 0959-6526, doi:10.1016/j.jclepro. 2014.07.073

[74] R. K. Bhushan, Optimization of cutting parameters for minimizing power consumption and maximizing tool life during machining of $\mathrm{Al}$ alloy $\mathrm{SiC}$ particle composites, Journal of Cleaner Production 39 (2013) 242-254, ISSN 0959-6526, doi: 10.1016/j.jclepro.2012.08.008

[75] M. Mori, M. Fujishima, Y. Inamasu, Y. Oda, A study on energy efficiency improvement for machine tools, CIRP Annals 60 (1) (2011) 145-148, ISSN 0007-8506, doi:10.1016/j.cirp. 2011.03.099

[76] Y. Halevi, E. Carpanzano, G. Montalbano, Y. Koren, Minimum energy control of redundant actuation machine tools, 
CIRP Annals 60 (1) (2011) 433-436, ISSN 0007-8506, doi: 10.1016/j.cirp.2011.03.032

[77] P. Liu, F. Liu, H. Qiu, A novel approach for acquiring the real-time energy efficiency of machine tools, Energy 121 (2017) 524-532, ISSN 0360-5442, doi:10.1016/j.energy.2017.01.047

[78] P. Albertelli, Energy saving opportunities in direct drive machine tool spindles, Journal of Cleaner Production 165 (2017) 855-873, ISSN 0959-6526, doi:10.1016/j.jclepro.2017.07.175

[79] I. F. Edem, P. T. Mativenga, Modelling of energy demand from computer numerical control (CNC) toolpaths, Journal of Cleaner Production 157 (2017) 310-321, ISSN 0959-6526, doi: 10.1016/j.jclepro.2017.04.096

[80] J. Lv, R. Tang, S. Jia, Y. Liu, Experimental study on energy consumption of computer numerical control machine tools, Journal of Cleaner Production 112 (2016) 3864-3874, ISSN 0959-6526, doi:10.1016/j.jclepro.2015.07.040

[81] Z. Bi, L. Wang, Optimization of machining processes from the perspective of energy consumption: A case study, Journal of Manufacturing Systems 31 (4) (2012) 420-428, ISSN 0278-6125, doi:10.1016/j.jmsy.2012.07.002, selected Papers of 40th North American Manufacturing Research Conference.

[82] E. Uhlmann, S. Thom, M. Ehricke, Application of Spindle Speed Increaser as Sustainable Solution to Upgrade Machine Tools, Procedia Manufacturing 8 (2017) 680-685, ISSN 23519789, doi:10.1016/j.promfg.2017.02.087 14th Global Conference on Sustainable Manufacturing, GCSM 3-5 October 2016, Stellenbosch, South Africa.

[83] R. Neugebauer, W. Drossel, R. Wertheim, C. Hochmuth, M. Dix, Resource and Energy Efficiency in Machining Using High-Performance and Hybrid Processes, Procedia CIRP 1 (2012) 3-16, ISSN 2212-8271, doi:10.1016/j.procir.2012.04.002 fifth CIRP Conference on High Performance Cutting 2012.

[84] H. Hegab, B. Darras, H. Kishawy, Towards sustainability assessment of machining processes, Journal of Cleaner Production 170 (2018) 694-703, ISSN 0959-6526, doi:10.1016/j. jclepro.2017.09.197

[85] R. X. Gao, P. Wang, Through Life Analysis for Machine Tools: From Design to Remanufacture, Procedia CIRP 59 (2017) 2-7, ISSN 2212-8271, doi:10.1016/j.procir.2016.09.027 proceedings of the 5th International Conference in Through-life Engineering Services Cranfield University, 1st and 2nd November 2016.

[86] E. Uhlmann, K.-D. Lang, L. Prasol, S. Thom, B. Peukert, S. Benecke, E. Wagner, F. Sammler, S. Richarz, N. F. Nissen, Sustainable Solutions for Machine Tools, Springer International Publishing, Cham, ISBN 978-3-319-48514-0, 47-69, doi:10.1007/978-3-319-48514-0_4 2017.

[87] R. Kumar, N. S. Kumar, H. Kishawy, A Novel Technique to Achieve Sustainable Machining System, Procedia CIRP 40 (2016) 30-34, ISSN 2212-8271, doi:10.1016/j.procir.2016.01. 045 13th Global Conference on Sustainable Manufacturing Decoupling Growth from Resource Use.

[88] A. Bruzzone, D. Anghinolfi, M. Paolucci, F. Tonelli, Energyaware scheduling for improving manufacturing process sustainability: A mathematical model for flexible flow shops, CIRP Annals 61 (1) (2012) 459-462, ISSN 0007-8506, doi: 10.1016/j.cirp.2012.03.084

[89] C. Lu, L. Gao, X. Li, Q. Pan, Q. Wang, Energy-efficient permutation flow shop scheduling problem using a hybrid multiobjective backtracking search algorithm, Journal of Cleaner Production 144 (2017) 228-238, ISSN 0959-6526, doi:10.1016/ j.jclepro.2017.01.011.

[90] Z. Sun, L. Li, M. Fernandez, J. Wang, Inventory control for peak electricity demand reduction of manufacturing systems considering the tradeoff between production loss and energy savings, Journal of Cleaner Production 82 (2014) 84-93, ISSN 0959-6526, doi:10.1016/j.jclepro.2014.06.071

[91] H. Suwa, T. Samukawa, A New Framework of Energy-efficient Manufacturing Systems Based on Energy Load Profiles, Procedia CIRP 41 (2016) 313-317, ISSN 2212-8271, doi:10.1016/j. procir.2015.10.011, research and Innovation in Manufacturing: Key Enabling Technologies for the Factories of the Future -
Proceedings of the 48th CIRP Conference on Manufacturing Systems.

[92] A. Piccinini, F. Previdi, C. Cimini, R. Pinto, F. Pirola, Discrete event simulation for the reconfiguration of a flexible manufactuing plant, IFAC-PapersOnLine 51 (11) (2018) 465-470, ISSN 2405-8963, doi:10.1016/j.ifacol.2018.08.362

[93] A. C. Roemer, S. Strassburger, A review of literature on simulation-based optimization of the energy efficiency in production, in: 2016 Winter Simulation Conference (WSC), IEEE, doi:10.1109/wsc.2016.7822194, 2016.

[94] B. Vogel-Heuser, C. Diedrich, D. Pantförder, P. Göhner, Coupling heterogeneous production systems by a multi-agent based cyber-physical production system, 12th IEEE International Conference on Industrial Informatics (INDIN) (2014) 713-719.

[95] J.-I. Latorre-Biel, J. Faulín, A. Juan, E. Jiménez-Macías, Petri Net Model of a Smart Factory in the Frame of Industry 4.0, IFAC-PapersOnLine 51 (2) (2018) 266-271, ISSN 2405-8963, doi:10.1016/j.ifacol.2018.03.046, 9th Vienna International Conference on Mathematical Modelling.

[96] C. Papadopoulos, J. Li, M. O'Kelly, A classification and review of timed Markov models of manufacturing systems, Computers \& Industrial Engineering 128 (2019) 219-244, ISSN 0360-8352, doi:10.1016/j.cie.2018.12.019

[97] O. V. Arriaza, D. Kim, D. Y. Lee, M. A. Suhaimi, Tradeoff analysis between machining time and energy consumption in impeller NC machining, Robotics and Computer-Integrated Manufacturing 43 (Supplement C) (2017) 164-170, ISSN 07365845, doi:10.1016/j.rcim.2015.09.014 special Issue: Extended Papers Selected from FAIM 2014.

[98] R. Baheti, H. Gill, Cyber-physical systems, in: The Impact of Control Technology, IEEE Control Systems Society, 161-166, 2011.

[99] L. Monostori, B. Kádár, T. Bauernhansl, S. Kondoh, S. Kumara, G. Reinhart, O. Sauer, G. Schuh, W. Sihn, K. Ueda, Cyber-physical systems in manufacturing, CIRP Annals 65 (2) (2016) 621-641, doi:10.1016/j.cirp.2016.06.005

100] Z. Jakovljevic, V. Majstorovic, S. Stojadinovic, S. Zivkovic, N. Gligorijevic, M. Pajic, Cyber-Physical Manufacturing Systems (CPMS), Springer International Publishing, ISBN 978-3-319-56430-2, 199-214, doi:10.1007/978-3-319-56430-2_ 14. 2017.

101] M. M. Herterich, F. Uebernickel, W. Brenner, The Impact of Cyber-physical Systems on Industrial Services in Manufacturing, Procedia CIRP 30 (Supplement C) (2015) 323328, ISSN 2212-8271, doi:10.1016/j.procir.2015.02.110, 7th Industrial Product-Service Systems Conference - PSS, industry transformation for sustainability and business.

[102] Y. S. Tan, Y. T. Ng, J. S. C. Low, Internet-of-Things Enabled Real-time Monitoring of Energy Efficiency on Manufacturing Shop Floors, Procedia CIRP 61 (Supplement C) (2017) 376381, ISSN 2212-8271, doi:10.1016/j.procir.2016.11.242, the 24th CIRP Conference on Life Cycle Engineering.

$103]$ E. Abele, P. Schraml, D. Moog, Electric Load Management on Machine Tools, Procedia CIRP 55 (2016) 164-169, ISSN 22128271, doi:10.1016/j.procir.2016.08.046, 5th CIRP Global Web Conference - Research and Innovation for Future Production (CIRPe 2016).

[104] H. S. Kang, J. Y. Lee, S. Choi, H. Kim, J. H. Park, J. Y. Son, B. H. Kim, S. D. Noh, Smart manufacturing: Past research, present findings, and future directions, International Journal of Precision Engineering and Manufacturing-Green Technology 3 (1) (2016) 111-128, doi:10.1007/s40684-016-0015-5

[105] O. Givehchi, J. Jasperneite, Industrial Automation Services as part of the Cloud: First Experiences, 2013.

[106] V. Filipov, P. Vasilev, Manufacturing Operations Management - The Smart Backbone Of Industry 4.0, in: SCIENTIFIC PROCEEDINGS I INTERNATIONAL SCIENTIFIC CONFERENCE INDUSTRY 4.0, vol. 1, ISSN 1310-3946, 71-76, 2016.

[107] T. Nguyen, M. Djeziri, B. Ananou, M. Ouladsine, J. Pinaton, Fault prognosis for Discrete Manufacturing Processes, IFAC 
Proceedings Volumes 47 (3) (2014) 8066-8072, ISSN 14746670 , doi:10.3182/20140824-6-ZA-1003.01514 19th IFAC World Congress.

[108] R. Stetter, P. Witczak, C. Spindler, J. Hertel, M. Witczak, Intelligent Systems for the Prognosis of Energy Consumption in Manufacturing and Assembly, Procedia CIRP 33 (2015) 370375, ISSN 2212-8271, doi:10.1016/j.procir.2015.06.084 9th CIRP Conference on Intelligent Computation in Manufacturing Engineering - CIRP ICME ' 14.

[109] D. Wu, S. Liu, L. Zhang, J. Terpenny, R. Gao, T. Kurfess, J. Guzzo, A fog computing-based framework for process monitoring and prognosis in cyber-manufacturing, Journal of Manufacturing Systems 43 (2017) 25-34, ISSN 0278-6125, doi: 10.1016/j.jmsy.2017.02.011

[110] S. Ubach, J. Diaz, C. Ocampo-Martinez, M. Antunez, Peak shaving through closed-loop optimization applied to machine tools with periodic behaviour, in: 2017 IEEE 3rd Colombian Conference on Automatic Control (CCAC), 1-7, doi:10.1109/ CCAC.2017.8276433 2017.

[111] D. J. Nativ, A. Cataldo, R. Scattolini, B. D. Schutter, Model Predictive Control of an Automated Storage/Retrieval System, IFAC-PapersOnLine 49 (12) (2016) 1335-1340, ISSN 24058963, doi:10.1016/j.ifacol.2016.07.745 8th IFAC Conference on Manufacturing Modelling, Management and Control MIM 2016.

[112] A. Kapitanov, Manufacturing System Flexibility Control, Procedia Engineering 206 (2017) 1470-1475, ISSN 1877-7058, doi: 10.1016/j.proeng.2017.10.663 international Conference on Industrial Engineering, ICIE 2017.

[113] A. Cataldo, A. Perizzato, R. Scattolini, Production scheduling of parallel machines with model predictive control, Control Engineering Practice 42 (2015) 28-40, ISSN 0967-0661, doi: 10.1016/j.conengprac.2015.05.007

[114] J. Zou, Q. Chang, J. Arinez, G. Xiao, Data-driven modeling and real-time distributed control for energy efficient manufacturing systems, Energy 127 (Supplement C) (2017) 247-257, ISSN 0360-5442, doi:10.1016/j.energy.2017.03.123

[115] C. Bauerdick, M. Helfert, B. Menz, E. Abele, A Common Software Framework for Energy Data Based Monitoring and Controlling for Machine Power Peak Reduction and Workpiece Quality Improvements, Procedia CIRP 61 (2017) 359-364, ISSN 2212-8271, doi:10.1016/j.procir.2016.11.226 the 24th CIRP Conference on Life Cycle Engineering.

[116] M. Krones, E. Müller, An Approach for Reducing Energy Consumption in Factories by Providing Suitable Energy Efficiency Measures, Procedia CIRP 17 (2014) 505-510, ISSN 2212-8271, doi:10.1016/j.procir.2014.01.045, variety Management in Manufacturing.

[117] Intel, Smart Transportation Robots Streamline Manufacturing Operations, URL https://software.intel.com/en-us/ articles/ 2018.

[118] S. Jeschke, C. Brecher, H. Song, D. Rawat (Eds.), Industrial Internet of Things, Springer International Publishing, doi:10. 1007/978-3-319-42559-7, 2017.

[119] Department of Energy (DOE), Chapter 6: Innovating Clean Energy Technologies in Advanced Manufacturing, Tech. Rep., Department of Energy (DOE), 2015.

[120] M. Mnati, A. Van den Bossche, R. Chisab, A smart voltage and current monitoring system for three phase inverters using an android smartphone application, Sensors 17 (4) (2017) 872.

[121] J. Fitzgerald, A. Mussomeli, A. Daecher, M. Chandramouli, Using smart sensors to drive supply chain innovation - A series exploring Industry 4.0 technologies and their potential impact for enabling digital supply networks in manufacturing, Tech. Rep., Deloitte, 2017.

[122] S. Mukhopadhyay (Ed.), Internet of Things: Challenges and Opportunities, Springer International Publishing, doi:10.1007/ 978-3-319-04223-7. 2014.

[123] Microsoft, Addressing ROI in Internet of Things Solutions, Tech. Rep., Department of Energy (DOE), 2016.

[124] L. Columbus, 2017 Roundup Of Internet Of
Things Forecasts, Forbes URL https://www . forbes.com/sites/louiscolumbus/2017/12/10/ 2017-roundup-of-internet-of-things-forecasts / \#56cbc5ab1480 